\title{
Long-range allosteric effects - How adenine nucleotides shape the conformational landscape of the Ski2-like RNA helicase, Brr2
}

Eva Absmeier ${ }^{1, \dagger, \infty}$, Karen Vester ${ }^{1, \dagger}$, Tahereh Ghane ${ }^{2}$, Dmitry Burakovskiy ${ }^{3, \$}$, Pohl Milon ${ }^{4}$, Petra Imhof ${ }^{2, \pi}$, Marina V. Rodnina ${ }^{3}$, Karine F. Santos ${ }^{1, \dagger, \#, *}$, Markus C. Wahl ${ }^{1,5, *}$

From the ${ }^{1}$ Freie Universität Berlin, Structural Biochemistry, Takustr. 6, D-14195 Berlin, Germany; ${ }^{2}$ Freie Universität Berlin, Computational Biophysics, Arnimallee 14, D-14195 Berlin, Germany; ${ }^{3}$ Max Planck Institute for Biophysical Chemistry, Department of Physical Biochemistry, Am Faßberg 11, D-37077

Göttingen, Germany; ${ }^{4}$ Centre for Research and Innovation, Health Sciences Faculty, Universidad Peruana de Ciencias Aplicadas, Lima, 15023, Perú; ${ }^{5}$ Helmholtz-Zentrum Berlin für Materialien und Energie, Macromolecular Crystallography, Albert-Einstein-Straße 15, D-12489 Berlin, Germany

$\dagger \quad$ These authors contributed equally to this work.

$\infty$ Present address: MRC Laboratory of Molecular Biology, Francis Crick Avenue, Cambridge CB2 0QH, UK

\$ Present address: Evotec SE, Essener Bogen 7, D-22419 Hamburg, Germany

I $\quad$ Present address: Friedrich-Alexander Universität Erlangen-Nürnberg, Department of Chemistry and Pharmacy, Computational Chemistry Center, Nägelsbachstr. 25, D-91052 Erlangen, Germany

\# Present address: 4TEEN4 Pharmaceuticals GmbH, Neuendorfstr. 15b, D-16761 Hennigsdorf, Germany

* To whom correspondence should be addressed: Karine F. Santos Bourgeois: 4TEEN4 Pharmaceuticals GmbH, Neuendorfstr. 15b, D-16761 Hennigsdorf, Germany; bourgeois @4teen4.de; Markus C. Wahl: Freie Universität Berlin, Structural Biochemistry, Takustr. 6, D-14195 Berlin, Germany; mwahl@zedat.fu-berlin.de; Tel.: +49-30-838-53456; Fax: +49-30-8384-53456

Running title: Long-range allosteric effects in an RNA helicase

Keywords: Allosteric regulation, enzyme kinetics, intra-molecular regulation, pre-mRNA splicing, protein conformation, RNA helicase, superfamily 2 helicase

\begin{abstract}
Brr2 is an essential Ski2-like RNA helicase that exhibits a unique structure among the spliceosomal helicases. Brr2 harbors a catalytically active Nterminal helicase cassette and a structurally similar, but enzymatically inactive C-terminal helicase cassette. Both cassettes contain a nucleotide binding pocket. Here we use biophysical and computational methods to delineate the functional connectivity between the cassettes and how occupancy of the nucleotide binding sites may influence each other. Our results show that Brr2 exhibits high specificity for adenine nucleotides with both cassettes binding ADP tighter than ATP.
\end{abstract}

Adenine nucleotide affinity for the inactive Cterminal cassette is more than two orders of magnitude higher than that of the active $\mathrm{N}$-terminal cassette, largely determined by slow nucleotide release. Mutations at the inter-cassette surfaces and in the connecting linker diminish the affinity of adenine nucleotides for both cassettes. Abrogation of nucleotide binding at the C-terminal cassette reduces nucleotide binding at the $\mathrm{N}$-terminal cassette, $70 \AA$ away. Molecular dynamics simulations identified structural communication lines that likely mediate the long-range allosteric effects. Together, our results reveal intricate networks of intra-molecular interactions in the 
complex Brr2 RNA helicase, which fine-tune its nucleotide affinities and which could be exploited for regulating the enzyme during splicing.

\section{INTRODUCTION}

Ski2-like nucleic acid helicases constitute a family of superfamily 2 (SF2) helicases. All Ski2like helicases display a common helicase core consisting of two RecA-like domains, a wingedhelix (WH) domain and a helical bundle (HB or "ratchet") domain arranged in a ring-like fashion (1). This domain arrangement has also been observed in structures of the DEAH/RHA family of SF2 helicases (2-4). Additionally, Ski2-like helicases can contain diverse accessory domains appended to or inserted into the conserved domains, which modulate or expand their molecular mechanisms or functions (5).

The two RecA-like domains contain twelve conserved sequence motifs ("helicase motifs") involved in nucleotide tri-phosphate (NTP) and nucleic acid transactions (6). Nucleic acid substrates bind with 3'-to-5' directionality across the first and second RecA-like domains and below the HB/ratchet domain, explaining the 3'-to-5' unwinding directionality of these enzymes (7-9). Ski2-like helicases also contain a $\beta$-hairpin in the second RecA-like domain, which is shorter compared to a similar element in DEAH/RHA helicases, and which is thought to act as a strand separation device that inserts between the two strands of a duplex when one strand of the substrate is pulled through the helicase unit $(8,10)$. Like DEAD-box helicases, Ski2-like helicases are thought to selectively utilize ATP due to the presence of a Q-motif (11).

Four Ski2-like RNA helicases have been identified in yeast: Ski2 (involved in RNA degradation and viral defense) (12), Slh1 (ribosome quality control) (13), Mtr4 (RNA degradation) (7) and Brr2 (pre-mRNA splicing) (14). In addition, an Mtr4 homolog, FRH, of Neurospora crassa is involved in the regulation of the circadian rhythm (15). Several additional Ski2-like enzymes are DNA helicases such as yeast Mer3/mammalian HFM1, involved in homologous recombination $(16,17)$, archaeal Hel308/eukaryotic POLQ-like helicase, involved in double strand break repair $(8,18)$, and the mammalian ASCC3 helicase, associated with transcription regulation (19), DNA repair (20), ribosome quality control (21-23), non- functional ribosomal RNA decay (24) and viral defense (25). 3'-to-5' translocation has been directly shown for Hel308 (8), Mer3/HFM1 (26), Mtr4 (27) and Brr2 $(28,29)$.

A common feature among Ski2-like RNA helicases is their integration into multi-protein assemblies. Brr2 is an integral component of the spliceosomal U5 snRNP (30,31). Thus, during assembly of a spliceosome on a pre-mRNA substrate, Brr2 is recruited as part of the preassembled U4/U6•U5 tri-snRNP during formation of a pre-catalytic B complex spliceosome (32-34). Brr2 is essential for the conversion of the precatalytic to an activated spliceosome $(35,36)$, during which it unwinds the extensively basepaired U4/U6 di-snRNA $(14,37,38)$. To this end, the enzyme binds to a single-stranded (ss) region of U4 snRNA and translocates in $3^{\prime}$-to-5' direction $(28,38)$. Unlike other spliceosomal helicases, Brr2 remains stably associated with the spliceosome after incorporation of the tri-snRNP throughout the remaining stages of a splicing event $(32,34,39-44)$, and is required again during the two catalytic steps of splicing $(45,46)$ and during spliceosome disassembly (47). However, the Brr2 helicase activity per se may not be necessary during these later stages of splicing $(43,45)$. Thus, Brr2 has to be strictly regulated to prevent premature unwinding of U4/U6 in the tri-snRNP and to allow its repeated on- and off-switching during splicing.

Brr2 is a particularly large spliceosomal RNA helicase (ca. $245 \mathrm{kDa}$ for the human enzyme). The helicase core of Brr2 is expanded by additional helix-loop-helix (HLH) and immunoglobulin-like (IG) domains, which form a Sec63-homology unit together with the $\mathrm{HB} /$ ratchet domain $(48,49)$. In addition, Brr 2 contains two copies of the RecA1/2WH-Sec63 units (cassettes) arranged in tandem (Fig. 1A) (50). This dual-cassette organization is shared by only few other Ski2-like enzymes, including the RNA helicase Slh1 (51) and the DNA helicase ASCC3 (20). Only the N-terminal cassette (NC) of Brr2 is an active ATPase and RNA helicase (50) and the enzymatic activity of the NC alone is required for splicing in vivo (52). Nevertheless, the C-terminal cassette (CC) is essential for yeast viability (49), represents a versatile protein-protein interaction platform $(53,54)$, retains nucleotide binding capacity $(50,55)$ and regulates the activity of the NC (50). Therefore, the CC may be 
considered an intra-molecular helicase cofactor in Brr2.

Preceding its two helicase cassettes, Brr2 contains an evolutionarily conserved $\mathrm{N}$-terminal region (NTR) of approximately 400 residues (Fig. 1A), capable of auto-inhibiting Brr2 (56). The NTR contains two folded domains connected by flexible regions and can fold back along one flank of the tandem helicase cassettes (Fig. 1B), blocking access of the RNA substrate and restricting conformational rearrangements required for RNA duplex unwinding (56). In vivo, the NTR is required for yeast viability, efficient splicing, Brr2 association with the U4/U6•U5 tri-snRNP, trisnRNP stability $(56,57)$, retention of U5 and U6 snRNAs during spliceosome activation (36) and as a protein-protein interaction platform (58).

Mechanistic insights into nucleotide binding, hydrolysis and product release are necessary to understand how NTP transactions are coupled to RNA rearrangements in RNA helicases. In spite of detailed structural analyses of the Brr2 helicase $(50,55,56,59)$, there is limited information about the molecular mechanisms underlying its NTPase cycle. Here, we used biophysical and computational methods to systematically characterize nucleotide binding to wild type (wt) Brr2 and selected variants. Our results show that the Brr2 helicase cassettes have drastically different affinities to nucleotides and that ADP is preferred over ATP in both nucleotide binding pockets. Residue exchanges at the inter-cassette interface reduced nucleotide association for both cassettes and mutations in the $\mathrm{CC}$ nucleotide-binding pocket interfered with nucleotide binding at the NC. We delineated structural communication lines in the enzyme by molecular dynamics simulations, which may mediate these long-range effects. Our results show that accessory regions in an RNA helicase ( $\mathrm{CC}$ in the case of Brr2) can regulate nucleotide affinity and specificity in an intricate manner.

\section{RESULTS \\ Nucleotide specificity of human Brr2}

We used recombinant human Brr2 (hBrr2), which we consider a good representative of all Brr2 orthologs, as Brr2 is evolutionarily highly conserved. Apart from full-length hBrr2, we investigated an N-terminally truncated variant (T1) that lacks most of the auto-inhibitory $\mathrm{N}$-terminal region as well as the isolated helicase cassettes (hBrr2 ${ }^{\mathrm{NC}}$, hBrr2 ${ }^{\mathrm{CC}}$; Fig. 1A).

$\mathrm{hBrr} 2$ has two nucleotide binding pockets, one in each of its cassettes (50) (Fig. 1A). The CC pocket is inactive in ATP hydrolysis (50). We first set out to directly test nucleotide binding preferences for each cassette of $\mathrm{hBrr} 2$ in isolation, $\mathrm{hBrr}^{\mathrm{NC}}$ (residues 395-1324) and $\mathrm{hBrr} 2^{\mathrm{CC}}$ (residues 1282-2136), making use of fluorescence resonance energy transfer (FRET) from tryptophan residues in the vicinity of the $\mathrm{NC}$ and $\mathrm{CC}$ nucleotide binding pockets (Trp817 in $\mathrm{hBrr} 2^{\mathrm{NC}}$ or Trp1652 and Trp1393 in hBrr2 ${ }^{\mathrm{CC}}$ ) to mant-nucleotides. In our experimental setups, excitation of tryptophans resulted in mant fluorescence increases upon binding of the labeled nucleotides; conversely, dissociation of the mant-nucleotides resulted in decreased FRET. Time courses of binding were recorded at a constant concentration of $\mathrm{hBrr} 2^{\mathrm{NC}}$ or $\mathrm{hBrr} 2^{\mathrm{CC}}(0.5 \mu \mathrm{M})$ with an excess of mantnucleotide (5 $\mu \mathrm{M}$; Fig. 2). Among the mantnucleotides tested (ADP, ATP, ATP $\gamma$ S, AMPPNP, GDP, GTP, GTP $\gamma$ S), only mant-ADP and mantATP $\gamma$ S showed FRET with both $h B r r 2^{\mathrm{NC}}$ and hBrr2 ${ }^{\mathrm{CC}}$ (Fig. 2A,B). mant-ATP only yielded a FRET signal with $\mathrm{hBrr} 2^{\mathrm{CC}}$, but not with $\mathrm{hBrr} 2^{\mathrm{NC}}$ (Fig. 2A,B). None of the guanosine nucleotides showed binding to either cassette.

These data show that both cassettes of hBrr2 possess a high specificity for adenine nucleotides, as expected from the presence of Q-motifs in the RecA1 domains of both cassettes, and suggested that both preferentially bind ADP over ATP $\gamma$ S.

\section{Structures of mant-nucleotides bound at NC and CC}

Lack of a FRET signal from mant-AMPPNP with either cassette (Fig. 2A,B) may indicate that AMPPNP is not a suitable ATP surrogate in the case of hBrr2. Similar observations have been made with GMPPNP and some GTPases (60). However, lack of a FRET signal from mant-ATP with $\mathrm{hBrr} 2^{\mathrm{NC}}$ was surprising, given that mant-ATP $\gamma \mathrm{S}$ yielded a signal (Fig. 2A,B). Based on this observation, we set out to investigate whether mant-nucleotides that give rise to FRET signals exhibit the same binding poses as the corresponding unlabeled nucleotides, and whether the mant moieties influence nucleotide binding. To this end, we determined crystal structures of $\mathrm{hBrr} 2$ in complex with ADP, ATP $\gamma \mathrm{S}$, mant-ADP and mant-ATP $\gamma \mathrm{S}$ at 2.5-2.8 $\AA$ resolution 
(Table S1). For crystallographic analyses, we used $\mathrm{N}$-terminally truncated $\mathrm{hBrr} 2^{\mathrm{T} 1}$ in complex with the Jab1 domain of the hPrp8 protein lacking a Brr2inhibiting C-terminal tail (hJab1 ${ }^{\Delta \mathrm{C}}$ ). The $\mathrm{hBrr} 2^{\mathrm{T1}}$ hJab1 ${ }^{\Delta \mathrm{C}}$ complex yields well-diffracting crystals under low-salt conditions (61), suitable for nucleotide binding.

Electron densities for the phosphate groups, the riboses and the adenine bases were well defined in both NC and CC for all nucleotides analyzed (Fig. 3A-D). At both cassettes, accommodation of the phosphate/ribose/base portions of mant-ADP and mant-ATP $\gamma \mathrm{S}$ were essentially unaltered compared to ADP and ATP $\gamma \mathrm{S}$ (Fig. 3A-D), showing that the mant units do not influence how the nucleotides are positioned in the binding pockets. Moreover, $\mathrm{ATP} \gamma \mathrm{S}$ and the ATP $\gamma \mathrm{S}$ portion of mant-ATP $\gamma \mathrm{S}$ are accommodated as expected for ATP (50). The structures also revealed that two tryptophan residues (W1393 and W1652) reside within $20 \AA$ distance of the CC nucleotide binding pocket, while only one tryptophan residue (W817) is close to the NC nucleotide binding pocket (Fig. S1), providing an explanation for higher FRET at the CC.

Additionally, electron densities for the mant units of mant-ADP and mant-ATP $\gamma \mathrm{S}$ were less defined in the NC compared to the CC (Fig. 3A-D), indicating that the fluorophores remain more mobile when mant-nucleotides are accommodated at the $\mathrm{NC}$ compared to the CC. With mant nucleotides bound at the NC, N820 (helicase motif Va) fosters a hydrogen bond to the mant moieties instead of the sugar units of unlabeled nucleotides (Fig. 3A-D, left). At the CC, mant moieties engage in additional van der Waals (vdW) contacts to the helicase motif Va residues (Fig. 3B,D, right).

Based on these results, we conclude that the mant moieties do not significantly alter the positioning of ADP or ATP $\gamma \mathrm{S}$ in the nucleotide binding pockets, but may lead to higher affinities of mant-nucleotides compared to the corresponding unmodified nucleotides by fostering additional contacts. The better defined electron densities for the mant moieties in the CC compared to the NC suggest that the mant units have a relatively larger effect on nucleotide affinities to the CC compared to the NC. Furthermore, comparable distances (within $\pm 0.2 \AA$ ) between mant moieties and close Trp residues in the structures with mant-ADP and mant-ATP $\gamma$ S (Fig. S1), suggest that higher FRET signals obtained with mant-ADP compared to
mant-ATP $\gamma \mathrm{S}$ (Fig. 2A,B) are due to a lower occupancy of the nucleotide binding pockets in the case of mant-ATP $\gamma \mathrm{S}$ under the chosen conditions, as a consequence of a lower affinity of ATP $\gamma \mathrm{S}$ compared to ADP. In addition, we suggest that $\mathrm{hBrr} 2^{\mathrm{NC}}$ exhibits higher conformational flexibility than the NC in context of a dual-cassette Brr2 construct ( $\mathrm{hBrr} 2^{\mathrm{T} 1}$ or $\mathrm{hBrr} 2^{\mathrm{FL}}$ ), and that, therefore, mant-ATP is not sufficiently stably bound at the isolated NC to yield a FRET signal (Fig. 2A).

We were predominantly interested in affinity changes due to allosteric effects, which we expect to affect mant-nucleotides and unmodified nucleotides in a similar manner. We, thus, concluded that mant-ADP and mant-ATP $\gamma \mathrm{S}$ are suitable surrogates for studying the binding of ADP and ATP to the Brr2 nucleotide binding pockets and, therefore, employed these nucleotides in subsequent experiments.

\section{Affinities of the isolated $N$ - and C-terminal cassettes of hBrr2 for adenine nucleotides}

Our initial investigations on the nucleotide specificity of the $\mathrm{hBrr} 2$ cassettes in isolation indicated that $\mathrm{hBrr} 2^{\mathrm{NC}}$ and $\mathrm{hBrr} 2^{\mathrm{CC}}$ bind nucleotides with different rates. To determine the nucleotide association rate constants, $k_{l}^{N C}$ and $k_{l}^{C C}$, and the equilibrium affinity constants, we investigated mant-ATP $\gamma \mathrm{S} /$ mant-ADP binding to $\mathrm{hBrr} 2^{\mathrm{NC}}$ and $\mathrm{hBrr} 2^{\mathrm{CC}}$ using strategies previously described for $\mathrm{G}$ nucleotide binding to translation factor GTPases (62-65).

We acquired time courses of binding at a constant concentration of nucleotide-free $\mathrm{hBrr} 2^{\mathrm{NC}}$ or $\mathrm{hBrr} 2^{\mathrm{CC}}$ and varying concentrations of mantATP $\gamma \mathrm{S} /$ mant-ADP under pseudo-first order conditions (Fig. 4A,B). The time dependencies of FRET were analyzed by exponential fitting to calculate the apparent rate constant of nucleotide binding to either cassette at each nucleotide concentration $\left(k_{a p p}{ }^{N C}\right.$ and $\left.k_{a p p}{ }^{C C}\right) . \mathrm{hBrr} 2^{\mathrm{NC}}$ and $\mathrm{hBrr} 2^{\mathrm{CC}}$ time traces were best fit with a singleexponential equation, consistent with a one-step binding model (Fig. 4A,B). The bimolecular association rate constants, $k_{l}{ }^{N C}$ and $k_{l}{ }^{C C}$, were determined from the slopes of the linear dependences of $k_{a p p}{ }^{N C}$ and $k_{a p p}{ }^{C C}$, respectively, on the concentration of mant-ATP $\gamma$ S/mant-ADP (Fig. 4C,D; Table 1). The values obtained indicate that both isolated $\mathrm{hBrr} 2^{\mathrm{NC}}$ and $\mathrm{hBrr} 2^{\mathrm{CC}}$ bind $\mathrm{ADP}$ faster 
than ATP $\gamma$ S. Furthermore, hBrr2 $2^{\mathrm{NC}}$ binds both tested nucleotides faster than $\mathrm{hBrr} 2^{\mathrm{CC}}$.

The dissociation rate constants were determined by pre-forming $\mathrm{hBrr} 2^{\mathrm{NC} / \mathrm{CC}}$ complexes with mantADP or mant-ATP $\gamma \mathrm{S}$, and mixing the complexes with an excess of the respective unlabeled nucleotide, using a stopped-flow apparatus. Under these conditions, the rate of ADP/ATP $\gamma \mathrm{S}$ binding is limited by the rate of mant-ADP/mant-ATP $\gamma \mathrm{S}$ dissociation from $\mathrm{hBrr} 2^{\mathrm{NC}}$ or $\mathrm{hBrr} 2^{\mathrm{CC}}$. Rebinding of the mant-nucleotide is negligible due to the large excess of unlabeled nucleotide. Thus, the rate by which the mant fluorescence decreases equals the dissociation rate of the mant-nucleotide. Dissociation rate constants were obtained by single-exponential fitting of the time courses (Fig. $4 \mathrm{E}, \mathrm{F}$; Table 1). hBrr2 ${ }^{\mathrm{NC}}$ dissociation rates $\left(k-{ }_{-1}^{N C}\right)$ were $1.9 \pm 0.1 \mathrm{~s}^{-1}$ and $1.6 \pm 0.02$ for mant-ADP and mant-ATP $\gamma \mathrm{S}$, respectively. ADP and ATP $\gamma \mathrm{S}$ dissociation rates for $\mathrm{hBrr} 2^{\mathrm{CC}}\left(k_{-1}{ }^{C C}\right)$ were three orders of magnitude lower than for hBrr $2^{\mathrm{NC}}, 2 \pm 0.2$ $10^{-3} \mathrm{~s}^{-1}$ (Fig. 4E,F; Table 1).

The $K_{d}$ values for the interaction of ADP and $\mathrm{ATP} \gamma \mathrm{S}$ with $\mathrm{hBrr} 2^{\mathrm{NC}}$ and $\mathrm{hBrr} 2^{\mathrm{CC}}$ were calculated from the ratios of dissociation and association rate constants $\left(K_{d}^{\mathrm{NC}}=k-{ }_{-}^{N C} / k_{l}{ }^{N C} ; K_{d}^{\mathrm{CC}}=k_{-l}{ }^{C C} / k_{l}{ }^{C C}\right)$. Both $\mathrm{hBrr} 2^{\mathrm{NC}}$ (3-fold) and $\mathrm{hBrr} 2^{\mathrm{CC}}$ (7.5-fold) displayed a higher affinity toward ADP compared to ATP $\gamma \mathrm{S}$ (Table 2). Furthermore, hBrr2 ${ }^{\mathrm{CC}}$ has about 500-fold and about 200-fold higher affinities for ADP and ATP $\gamma \mathrm{S}$, respectively, as compared to $\mathrm{hBrr} 2^{\mathrm{NC}}$, largely determined by the dissociation rates $\left(k-1{ }^{C C}\right)$ for mant-nucleotides (Table 2). Thus, although the two helicase cassettes are structurally similar, they differ over more than two orders of magnitude in their capacity to interact with adenine nucleotides.

\section{Interaction of mant-ATP $\mathrm{S} S /$ mant-ADP with $h B r r 2^{F L}$ and $h B r r 2^{T I}$}

We next studied nucleotide binding behavior to $\mathrm{hBrr} 2^{\mathrm{FL}}$ and $\mathrm{hBrr} 2^{\mathrm{T} 1}$, using the same detection principles as described above. $\mathrm{hBrr} 2^{\mathrm{FL}}$ comprises the full-length helicase, whereas $\mathrm{hBrr} 2^{\mathrm{T} 1}$ lacks the NTR except for a segment that meanders along the NC (NC-clamp; Fig. 1A). The time courses of nucleotide binding were obtained at a constant concentration of nucleotide-free $\mathrm{hBrr} 2^{\mathrm{FL}}$ or $\mathrm{hBrr} 2^{\mathrm{T} 1}$ and a varying concentration of mant-ADP/mantATP $\gamma$ S. For both, hBrr $2^{\mathrm{FL}}$ and $\mathrm{hBrr} 2^{\mathrm{T} 1}$, biphasic time dependencies were observed (Fig. 5A,B), consistent with the nucleotides binding to the $\mathrm{NC}$ and $\mathrm{CC}$ of hBrr2. Nonlinear regression analysis using two exponential terms yielded two apparent rate constants, $k_{a p p l}$ and $k_{a p p 2}$, for each time trace. To assign each $k_{a p p}$ to $\mathrm{NC}$ or $\mathrm{CC}$, we integrated the results as for the isolated cassette constructs. $k_{a p p l}$ dependencies over nucleotide concentration were in the same range as those obtained with the isolated $\mathrm{hBrr} 2^{\mathrm{NC}}$, whereas $k_{\text {app } 2}$ dependencies roughly agreed with those of $\mathrm{hBrr} 2^{\mathrm{CC}}$, allowing assignment of each apparent rate constant to adenine nucleotide interaction with each cassette. The bimolecular association rate constants, $k_{l}^{N C}$ and $k_{l}{ }^{C C}$, were determined from the linear concentration dependences of $k_{a p p}{ }^{N C}$ and $k_{a p p}{ }^{C C}$ on the concentration of mant-nucleotides (Fig. 5C,D; Table 1).

The slope of the linear fitting of $k_{a p p}{ }^{N C}$, corresponding to the binding of mant-ADP to the $\mathrm{NC}$ in the context of $\mathrm{hBrr} 2^{\mathrm{FL}}$ and $\mathrm{hBrr} 2^{\mathrm{T} 1}$, indicated association rate constants $k_{l}^{N C}$ of $2.8 \pm 0.03$ and $2.5 \pm 0.11 \mu \mathrm{M}^{-1} \mathrm{~s}^{-1}$, respectively. The $k_{l}{ }^{N C}$ values obtained for mant-ATP $\gamma \mathrm{S}$ binding to the $\mathrm{NC}$ of $\mathrm{hBrr} 2^{\mathrm{FL}}$ and $\mathrm{hBrr} 2^{\mathrm{T} 1}$ were $1.0 \pm 0.02$ and $2.5 \pm 0.03$ $\mu \mathrm{M}^{-1} \mathrm{~s}^{-1}$, respectively. The mant-ADP and mantATP $\gamma \mathrm{S}$ association rates to the $\mathrm{NC}$ in the context of $\mathrm{hBrr} 2^{\mathrm{FL}}$ and $\mathrm{hBrr} 2^{\mathrm{Tl}}$ are thus ranging from 8 - to 3 fold faster compared to the rates of nucleotide binding to isolated hBrr2 $2^{\mathrm{NC}}\left(k_{l}{ }^{N C}\right.$ of $1.0 \pm 0.07 \mu \mathrm{M}^{-1}$ $\mathrm{s}^{-1}$ and $0.3 \pm 0.02$, respectively, for mant-ADP and mant-ATP $\gamma \mathrm{S})$, suggesting that the CC slightly improves the ability of the $\mathrm{NC}$ to bind nucleotides. These observations are in line with previous findings that $\mathrm{hBrr} 2^{\mathrm{NC}}$ exhibits lower intrinsic and stimulated ATPase activities and lower U4/U6 disnRNA unwinding activity compared to $\mathrm{hBrr} 2^{\mathrm{T} 1}$ (50).

Mant-ADP binding to the $\mathrm{CC}$ of $\mathrm{hBrr} 2^{\mathrm{FL}}$ and $\mathrm{hBrr} 2^{\mathrm{T} 1}$ was faster compared to mant-ATP $\gamma \mathrm{S}$, with an association rate constant, $k_{l}{ }^{C C}$, of $0.4 \pm 0.01 \mu \mathrm{M}^{-1}$ $\mathrm{s}^{-1}$ for both $\mathrm{hBrr} 2$ variants. The $\mathrm{hBrr} 2^{\mathrm{FL}}$ and $\mathrm{hBrr} 2^{\mathrm{T} 1}$ rate constants for mant-ATP $\gamma \mathrm{S}$ binding to the $\mathrm{CC}$, $k_{l}^{C C}$, were similar $\left(0.1 \pm 0.01 \mu \mathrm{M}^{-1} \mathrm{~s}^{-1}\right)$. These values agree well with the $k_{l}^{C C}$ obtained for mant-ADP and mant-ATP $\gamma \mathrm{S}$ binding to the isolated $\mathrm{hBrr} 2^{\mathrm{CC}}$, $0.5 \pm 0.01$ and $0.1 \pm 0.001 \mu \mathrm{M}^{-1} \mathrm{~s}^{-1}$, respectively, indicating that presence of the $\mathrm{NC}$ does not significantly influence nucleotide binding at the CC.

Nucleotide dissociation from $\mathrm{hBrr} 2^{\mathrm{FL}}$ and $\mathrm{hBrr} 2^{\mathrm{T} 1}$ was studied as before with the isolated 
$\mathrm{hBrr} 2^{\mathrm{NC}}$ and $\mathrm{hBrr} 2^{\mathrm{CC}}$ constructs. Nucleotide dissociation rate constants, $k-1^{N C}$ and $k-1{ }^{C C}$, were determined upon mixing $\mathrm{hBrr} 2^{\mathrm{FL} / \mathrm{T} 1}$-mant-ADP or $\mathrm{hBrr} 2^{\mathrm{FL} / \mathrm{T} 1}$-mant-ATP $\gamma \mathrm{S}$ with an excess of the respective unlabeled nucleotide. The release of the labeled nucleotide from both hBrr2 nucleotide binding pockets resulted in a two-phase fluorescence decrease, consistent with the dissociation of mant-ADP or mant-ATP $\gamma \mathrm{S}$ from the two hBrr2 cassettes (Fig. 5E,F). As nucleotide dissociation from the isolated $\mathrm{NC}$ was much faster than from the isolated $\mathrm{CC}$ (see above), the dissociation rate constants of the fast phases were assigned to the $\mathrm{NC}, k_{-1}^{N C}$. The nucleotide dissociation rate constants $k_{-}{ }^{N C}$ for $\mathrm{hBrr} 2^{\mathrm{FL}}$ and $\mathrm{hBrr} 2^{\mathrm{T} 1}$ were very similar, around $1.5 \pm 0.02$ $\left(\mathrm{hBrr} 2^{\mathrm{FL}}\right)$ and $1.3 \pm 0.02 \mathrm{~s}^{-1}\left(\mathrm{hBrr} 2^{\mathrm{Tl}}\right)$ for mant-ADP and around 1.5 $\pm 0.04 \mathrm{~s}^{-1}\left(\mathrm{hBrr}^{\mathrm{FL}}\right)$ and $1.2 \pm 0.04 \mathrm{~s}^{-1}$ $\left(\mathrm{hBrr} 2^{\mathrm{Tl}}\right.$ ) for mant-ATP $\gamma \mathrm{S}$ (Table 1). These values are in agreement with the $k-l^{N C}$ obtained for mant$\mathrm{ADP}$ and mant-ATP $\gamma \mathrm{S}$ in the isolated $\mathrm{hBrr} 2^{\mathrm{NC}}$ $\left(1.9 \pm 0.1 \mathrm{~s}^{-1}\right.$ and $1.6 \pm 0.02$, respectively). The second phase indicated very slow nucleotide release from the $\mathrm{CC}$ in the context of $\mathrm{hBrr} 2^{\mathrm{FL}}$ and $\mathrm{hBrr} 2^{\mathrm{T} 1}$, with a dissociation rate constant, $k-1_{-1}^{C C}$, of about $1 \pm 0.1$ $10^{-3} \mathrm{~s}^{-1}$ for ADP and ATP $\gamma \mathrm{S}$, similar to the values associated with the very slow release of nucleotides from isolated $\mathrm{hBrr} 2^{\mathrm{CC}}$. Therefore, the $\mathrm{CC}$ appears to be primarily a binding site where nucleotides interact and remain bound due to the low dissociation rate constants. The NC is a site of high turnover with rapid nucleotide binding and rapid release, consistent with its abilities to hydrolyze ATP and promote RNA unwinding (50).

The $K_{d}$ values for the interaction of ADP and ATP $\gamma \mathrm{S}$ with $\mathrm{hBrr} 2^{\mathrm{FL}}$ and $\mathrm{hBrr} 2^{\mathrm{T} 1}$ were also calculated from the ratios of the association $\left(k_{l}^{N C}\right.$ and $\left.k_{l}{ }^{C C}\right)$ and dissociation rate constants $\left(k_{-1}{ }^{N C}\right.$ and $\left.k_{-1}^{C C}\right)$. Due to the small dissociation rate constants, $k_{-1}^{C C}$, the CC nucleotide binding pockets in $\mathrm{hBrr} 2^{\mathrm{FL}} / \mathrm{hBrr} 2^{\mathrm{T} 1}$ have about 270 -fold/260-fold higher affinities for ADP and about 160-fold/50fold higher affinities for ATP $\gamma \mathrm{S}$, respectively, compared to the NC pocket (Table 2).

Both nucleotide binding pockets of $\mathrm{hBrr} 2^{\mathrm{FL}}$ exhibit slightly higher affinities for ADP than $\mathrm{ATP} \gamma \mathrm{S}$, with a 3-fold and 5-fold preference for ADP in the NC and CC, respectively. Upon NTR truncation $\left(\mathrm{hBrr} 2^{\mathrm{Tl}}\right)$, ADP and ATP $\gamma \mathrm{S}$ bind with equal affinities to the $\mathrm{NC}$, while the $\mathrm{CC}$ still has a five-fold higher affinity for ADP. Thus, presence of the NTR seems to bias the relative NC nucleotide preference towards ADP, which may contribute to its function as an auto-inhibitory device.

\section{Residues in the inter-cassette interface and linker modulate nucleotide binding at both cassettes}

Direct contacts of the NC RecA1 domain to the CC RecA2 domain observed in Brr2 crystal structures $(50,55,56,59)$ are candidate sites for inter-cassette communication (Fig. 1C, left). Indeed, single alanine substitutions expected to weaken interactions between the NC RecA1 and the CC RecA2 domains have been reported to reduce the helicase activity of $\mathrm{hBrr} 2^{\mathrm{T} 1}$ without affecting its RNA binding properties (50). The linker between $\mathrm{NC}$ and $\mathrm{CC}$ also establishes interaction networks between the cassettes, and alterations to the linker can likewise affect $\mathrm{hBrr} 2^{\mathrm{Tl}}$ helicase activity both positively and negatively (50). We therefore investigated if inter-cassette and linker mutants also affect nucleotide binding at either hBrr2 cassette. $\mathrm{hBrr} 2^{\mathrm{T} 1}$ mutants were expressed, purified and exhibited cooperative transitions with comparable melting temperatures in thermofluor-based thermal melting experiments (Fig. S2). Furthermore, equilibrium $\mathrm{CD}$ spectra were indicative of a high content of regular secondary structure in all hBrr2 variants. These data indicate that all $\mathrm{hBrr} 2^{\mathrm{T} 1}$ variants tested herein were well folded, and that mutant effects were not simply a result of a loss of stable tertiary structure.

Rate constants of nucleotide binding and dissociation to $\mathrm{hBrr} 2^{\mathrm{T} 1}$ mutants were determined as described above for the wt $\mathrm{hBrr} 2^{\mathrm{T} 1}$ protein. All association and dissociation time courses recorded for interface and linker mutants were best described by double-exponential fitting, representing the nucleotide binding and dissociation events at the $\mathrm{NC}$ and $\mathrm{CC}$. The bimolecular association rate constants for nucleotide binding at the $\mathrm{NC}$ and $\mathrm{CC}$, $k_{l}{ }^{N C}$ and $k_{l}{ }^{C C}$, were determined from the slope of the linear concentration dependence of the $k_{a p p}{ }^{N C}$ and $k_{a p p}{ }^{C C}$ (Table 1). Strikingly, all variants, R603A (NC-RecA1), R637A (NC-RecA1), PPP12961298AAA (linker) and H1548A (CC-RecA2; Fig. $1 \mathrm{C}$, left and middle), exhibited reduced ATP $\gamma \mathrm{S}$ association rate constants to the $\mathrm{NC}$ and $\mathrm{CC}$, while the dissociation rate constants for both cassettes were similar to those of $\mathrm{wt} \mathrm{hBrr2}{ }^{\mathrm{T} 1}$ (Fig. 6A,B). As a consequence, the resultant $K_{d}$ 's showed that the variant proteins bind $\mathrm{ATP} \gamma \mathrm{S}$ with lower affinity 
compared to wt $\mathrm{hBrr} 2^{\mathrm{T} 1}$. Interestingly, only one mutant had an effect on ADP binding. The R603A variant displayed about 10 -fold and about 20 -fold lower ADP association rate constants for $\mathrm{NC}$ and $\mathrm{CC}$, respectively, compared to wt $\mathrm{hBrr} 2^{\mathrm{T} 1}$ (Fig. 6C,D; Table 1). ADP dissociation rate constants of both cassettes were largely unaffected by the mutations (Fig. 6C,D; Table 1). In summary, all mutants reduced binding of ATP $\gamma \mathrm{S}$ to either cassette, one mutant (R603A) also reduced ADP binding to both cassettes, while the release of ADP or ATP $\gamma \mathrm{S}$ from either cassette was largely unaffected. Thus, inter-cassette contacts appear to configure the adenine nucleotide binding pockets for ATP binding. Interestingly, ATP $\gamma \mathrm{S}$ association rate constants to $\mathrm{hBrr} 2^{\mathrm{T} 1}$ variants with diminished inter-cassette contacts resemble those of the isolated $\mathrm{hBrr} 2^{\mathrm{NC}}$, suggesting that the regulatory $\mathrm{CC}$ requires those inter-cassette contacts to modulate the NC.

\section{Mutation of the C-terminal nucleotide binding pocket affects nucleotide binding at the $N$ - terminal cassette}

Mutations in motif I (Walker A motif or P-loop) of NTP-binding proteins and NTPases are known to interfere with nucleotide binding. In particular, a lysine residue in this motif is crucial for phosphate coordination and nucleotide stabilization (66). To test if nucleotide occupancy at the $\mathrm{CC}$ affects nucleotide binding at the $\mathrm{NC}$, we generated a GK1355-6QE variant of $\mathrm{hBrr} 2^{\mathrm{T} 1}$, bearing residue exchanges in motif $\mathrm{I}$ of the $\mathrm{CC}$ expected to abrogate nucleotide binding at the $\mathrm{CC}$ (Fig. 1C, right). Consistently, hBrr2 ${ }^{\mathrm{T} 1}$ GK1355-6QE nucleotide association and dissociation time courses were best described by a single exponential, indicating nucleotide binding at the NC only. The association rate constants for mant-ADP and mant-ATP $\gamma \mathrm{S}$ derived from the linear $k_{a p p}{ }^{N C}$ concentration dependence were more than 6-fold and about 2-fold slower, respectively, compared to the rates seen with wt hBrr2 ${ }^{\mathrm{T} 1}$ (Fig. 6E,F; Table 1). The dissociation rate constants for ATP $\gamma \mathrm{S}$ and ADP remained unchanged, as observed for the intercassette and linker mutants (Fig. 6E,F; Table 1). As a result, the $\mathrm{NC}$ nucleotide binding site of the GK1355-6QE mutant had about 2-fold and about 10-fold lower affinities for ADP and ATP $\gamma \mathrm{S}$, respectively, compared to the affinities displayed by the $\mathrm{NC}$ pocket of $\mathrm{wt} \mathrm{hBrr} 2^{\mathrm{T} 1}$. Thus, like the inter- cassette contacts, nucleotide binding at the $\mathrm{CC}$ also gears nucleotide affinities of the NC towards ATP.

\section{Molecular dynamics simulations suggest intra- molecular communication lines that might mediate long-range effects}

Our rapid kinetics experiments indicated that the inter-cassette interface and linker between NC and $\mathrm{CC}$ influence nucleotide binding at both cassettes. Additionally, nucleotide binding to the $\mathrm{CC}$ can modulate the kinetics of ADP and ATP interaction with the NC, some $70 \AA$ away. To delineate possible structural communication lines that could mediate these long-range effects, we conducted molecular dynamics (MD) simulations using available crystal structures of apo-hBrr2 ${ }^{\mathrm{T} 1}$ (PDB ID 4F91) and $\mathrm{hBrr} 2^{\mathrm{T} 1}$ with ADP bound at the $\mathrm{NC}$ and ATP bound at the CC (PDB ID 4F93) (50). By combining both crystal structures, we generated models of apo NC-CC (both nucleotide binding pockets empty), $\mathrm{NC}^{\mathrm{ADP}}-\mathrm{CC}$ (ADP bound at the $\mathrm{NC}$, CC empty), NC-CC ${ }^{\text {ATP }}$ (NC empty, ATP bound at the $\mathrm{CC}$ ), $\mathrm{NC}^{\mathrm{ADP}}-\mathrm{CC}^{\mathrm{ATP}}$ (ADP bound at the $\mathrm{NC}$, ATP bound at the CC) and $\mathrm{NC}^{\text {ATP }}{ }_{-} \mathrm{CC}^{\mathrm{ATP}}$ (ATP bound at either cassette) and monitored their equilibrium dynamics at $300 \mathrm{~K}$ for $200 \mathrm{~ns}$ after equilibration.

Based on the MD trajectories, we first analyzed fluctuations in atomic positions. No significant differences in the fluctuations of $\mathrm{C} \alpha$ positions in the $\mathrm{CC}$ were observed when comparing trajectories of models bearing empty or nucleotide-bound $\mathrm{CCs}$ (Fig. 7A, right). In contrast, the region around residue 750 of the NC (RecA2 domain, region between motifs IV and IVa, involved in RNA binding) showed increased flexibility in $\mathrm{NC}^{\mathrm{ADP}}-\mathrm{CC}$ and NC-CC ${ }^{\text {ATP }}$ (Fig. 7A, left). Fluctuations in this region were further increased when nucleotides were bound at both cassettes $\left(\mathrm{NC}^{\mathrm{ADP}}-\mathrm{CC}^{\mathrm{ATP}}\right.$ and $\mathrm{NC}^{\text {ATP }}-\mathrm{CC}^{\text {ATP }}$; Fig. 7A, left). Detailed comparison of the linear correlation of fluctuations for the $\mathrm{NC}$ RecA1-RecA2-WH region confirmed an increased movement, manifested by stronger anti-correlations (darker red regions), between RecA2 and the other two domains (in particular the WH domain; Fig. 7B). The degree of this anti-correlation was increased in the fully-filled models $\left(\mathrm{NC}^{\mathrm{ADP}}-\mathrm{CC}^{\mathrm{ATP}}\right.$ and $\mathrm{NC}^{\mathrm{ATP}}{ }_{-} \mathrm{CC}^{\mathrm{ATP}}$ ) compared to those with only one or no nucleotide bound ( $\mathrm{NC}^{\mathrm{ADP}}-\mathrm{CC}$ and $\mathrm{NC}$ $\mathrm{CC}^{\mathrm{ATP}}$; Fig. 7B). The anti-correlation was strongest for the $\mathrm{NC}^{\mathrm{ATP}}-\mathrm{CC}^{\mathrm{ATP}}$ model (Fig. $7 \mathrm{~B}$, boxed). 
Together, these observations indicate that nucleotide binding to the $\mathrm{NC}$ and $\mathrm{CC}$ leads to an additive increase in the flexibility of the region between motifs IV and IVa in the NC RecA2 domain.

We next quantified the distance distribution between G506 (motif I) and G854 (motif VI, involved in NTP binding/hydrolysis) in the NC as well as between corresponding residues in the $\mathrm{CC}$ (G1353 and G1689, respectively) as a measure for the widths of the nucleotide binding pockets in the MD trajectories of the various states. In the apo state, the NC pocket exhibited a bimodal width distribution with a predominant form around $7 \AA$ and a minor form around $5 \AA$ (Fig. 8A). Upon ADP binding to the $\mathrm{NC}$ alone ( $\left.\mathrm{NC}^{\mathrm{ADP}}-\mathrm{CC}\right)$, only the $7 \AA$ conformation remained (Fig. 8A). Upon additional binding of ATP to the $\mathrm{CC}\left(\mathrm{NC}^{\mathrm{ADP}}-\mathrm{CC}^{\mathrm{ATP}}\right)$, the $\mathrm{NC}$ pocket width was partially further increased, with a new distribution appearing at around $9 \AA$ (Fig. 8A). With ATP bound at both cassettes ( $\left.\mathrm{NC}^{\text {ATP }}-\mathrm{CC}^{\mathrm{ATP}}\right)$, the NC nucleotide binding pocket showed a monomodal width distribution around $8 \AA$ (Fig. $8 \mathrm{~A})$, i.e. intermediate between the widths seen in the bimodal $\mathrm{NC}^{\mathrm{ADP}}-\mathrm{CC}^{\mathrm{ATP}}$ distribution. ATP binding at the $\mathrm{CC}$ alone (NC-CC ${ }^{\mathrm{ATP}}$ ) shifted the bimodal distribution in the $\mathrm{NC}$ of the apo state (5 and $7 \AA$ ) to larger widths (7 and $9 \AA$ ). As for the $\mathrm{NC}$, the width of the $\mathrm{CC}$ nucleotide binding pocket was generally increased upon ATP binding (e.g. from around $4 \AA$ in NC-CC to about 6 or $5 \AA$ in NC$\mathrm{CC}^{\mathrm{ATP}}$ and $\mathrm{NC}^{\mathrm{ATP}} \mathrm{CC}^{\mathrm{ATP}}$, respectively; Fig. 8B). ADP binding at the $\mathrm{NC}$ had particularly pronounced effects on the $\mathrm{CC}$, increasing the nucleotide binding pocket of the latter cassette to about $8.5 \AA$ in NC ${ }^{\mathrm{ADP}}-\mathrm{CC}$ and to a bimodal $5 / 6 \AA$ distribution in $\mathrm{NC}^{\mathrm{ADP}}-\mathrm{CC}^{\mathrm{ATP}}$ (Fig. 8B). These observations show that nucleotide-bound configurations of both cassettes are generally associated with larger widths of the respective nucleotide binding pockets compared to the unoccupied states. Moreover, ATP binding at the $\mathrm{CC}$ generally induces conformations of the $\mathrm{NC}$ associated with wider nucleotide-binding pockets. Likewise, ADP binding at the NC generally leads to a wider nucleotide binding pocket at the $\mathrm{CC}$, while ATP at the NC might have a small effect in the opposite direction. Larger pockets and a trend towards bimodal distributions of the pocket widths upon nucleotide binding qualitatively agree with a higher flexibility of the motif IV-motif IVa region in the NC upon nucleotide binding (Fig. 7). Irrespective of the detailed effects, these results support the idea of structural communication between the two nucleotide binding pockets in hBrr2.

To elucidate a possible mechanism of increased flexibilities upon NTP binding, hydrogen bond formation in the pockets with and without bound NTPs was analyzed. In the NC, the average number of hydrogen-bonded contacts between the protein and ADP or ATP was comparable (Table S2). Notably, residues binding the nucleotides did not engage in alternative, intra-hBrr2 hydrogen bonds in the absence of nucleotides. Thus, the observed increase in flexibility of the motif IV-motif IVa region in the NC upon nucleotide binding cannot be explained by redirected hydrogen bonding. However, nucleotide binding at the $\mathrm{NC}$ led to additional hydrogen bonds between K509 (motif I) and the backbone of A503 (ATP bound) or P504 (ADP bound), as well as between the side chain of N482 (Q-motif) and the backbone of A507 (motif I; ADP bound). In addition to cross-strutting by the bound nucleotide, such additional intra-hBrr2 hydrogen bonding might explain the increase in melting temperatures observed for all hBrr2 variants upon addition of ATP (Fig. S2). Most notably, N482 formed hydrogen bonds to Q485, when the CC was empty, i.e. to the glutamine of the Q-motif that binds the base of adenine nucleotides. Such sequestration of the Q-motif provides an explanation for our observation of reduced adenine nucleotide binding at the NC in the GK1355-6QE variant (Fig. 6E,F), in which nucleotide binding at the $\mathrm{CC}$ is abrogated.

Analysis of hydrogen bonds between the protein and the nucleotides in the $\mathrm{CC}$ showed an increased number of hydrogen bonds in $\mathrm{NC}^{\mathrm{ADP}}-\mathrm{CC}^{\mathrm{ATP}}$ and $\mathrm{NC}^{\mathrm{ATP}}{ }_{-} \mathrm{CC}^{\mathrm{ATP}}(7.1 \pm 1.1$ and $6.8 \pm 1.1$ hydrogen bonds, respectively) compared to the NC-CC ${ }^{\text {ATP }}$ state (4.0 \pm 0.9 hydrogen bonds; Table S2). Interestingly, G1353 (motif I), whose distance to G1689 (motif VI) we used as a measure of the pocket width, was involved in hydrogen bonds to ATP in $\mathrm{NC}^{\text {ADP }}$ CC $^{\text {ATP }}$ and $\mathrm{NC}^{\text {ATP }}$-CC $^{\text {ATP }}$. As in the $\mathrm{NC}$, however, none of the residues binding the nucleotides via hydrogen bonds were engaged in intra-hBrr2 hydrogen bonds when the $\mathrm{CC}$ is unoccupied.

Finally, we sought to investigate the structural basis of long-range communication between the 
nucleotide binding pockets of the two cassettes, by which the CC pocket might influence nucleotide binding at the NC, and by which residues at the inter-cassette surfaces might exert their effects on nucleotide binding at either cassette. To this end, we extracted the shortest hydrogen-bonded paths, weighted by hydrogen-bond probabilities between residues along the path, between $\mathrm{NC}$ and $\mathrm{CC}$ nucleotide binding pockets from the MD trajectories of the various states (Fig. 9). Details of these shortest paths differed in the different MD trajectories. Model $\mathrm{NC}^{\text {ATP }}{ }_{-} \mathrm{CC}^{\mathrm{ATP}}$ exhibited the lowest diversity in shortest paths between the pocket residues (Fig. 9A). The helix containing T1578 (following motif IV ${ }^{\mathrm{CC}}$ ) was only involved in shortest paths in models $\mathrm{NC}-\mathrm{CC}^{\mathrm{ATP}}$ and $\mathrm{NC}^{\mathrm{ADP}}$ $\mathrm{CC}^{\mathrm{ATP}}$, whereas the helix that contains H1548 (preceding motif $\mathrm{IV}^{\mathrm{CC}}$ ) was part of shortest paths connecting the pocket residues in all models except for $\mathrm{NC}^{\mathrm{ADP}}{ }_{-} \mathrm{CC}^{\mathrm{ATP}}$ (Table 3). In the two models with $\mathrm{ADP}$ bound at the $\mathrm{NC}$, i.e. $\mathrm{NC}^{\mathrm{ADP}}-\mathrm{CC}$ and $\mathrm{NC}^{\mathrm{ADP}}$ $\mathrm{CC}^{\mathrm{ATP}}$, the shortest paths from K509 and T510 (motif $\mathrm{I}^{\mathrm{NC}}$ ) that ran along the backbone of the helix following motif $\mathrm{I}^{\mathrm{NC}}$ through a strong hydrogen bond between R647 (preceding motif III ${ }^{\mathrm{NC}}$ ) and E497 (between $\mathrm{Q}$ motif ${ }^{\mathrm{NC}}$ and motif $\mathrm{I}^{\mathrm{NC}}$ ) would provide a short-cut to motif III $^{\mathrm{NC}}$. The hydrogen bond-based communication between the two cassettes appears to be dominated by the highly probable hydrogen bonds between R603 (between motifs Ic ${ }^{\mathrm{NC}}$ and II ${ }^{\mathrm{NC}}$ ) and D1575 (helix following motif $\mathrm{IV}^{\mathrm{CC}}$ ), between R637 (between motifs $\mathrm{II}^{\mathrm{NC}}$ and $\mathrm{III}^{\mathrm{NC}}$ ) and D1583 (helix following motif $\mathrm{IV}^{\mathrm{CC}}$ ) and between E602 (between motifs $\mathrm{Ic}^{\mathrm{NC}}$ and $\mathrm{II}^{\mathrm{NC}}$ ) and $\mathrm{K} 1544$ (preceding motif $\mathrm{IV}^{\mathrm{CC}}$; Table S3). In all models, except for $\mathrm{NC}^{\mathrm{ATP}}-\mathrm{CC}^{\mathrm{ATP}}$, at least one shortest path between the nucleotide binding sites runs via R637 (Table 3). It is interesting to note that R637-D1583 is the interface crossing in some paths of the models with empty CC (Table S4), although in these models this hydrogen bond is less probable than in the other models (Table S3). In the NC-CC ${ }^{\text {ATP }}$ model the contrary is observed: the interface is crossed between R637 and D1583 (Table S4), which form a hydrogen bond throughout the course of the simulation, but residue 1583 is not contained in the shortest paths between active sites (Table 3). The interface is crossed from E602 to K1544 (Table $\mathrm{S} 4$ ), which is also the crossing point for model $\mathrm{NC}^{\text {ATP }}$ CC $^{\text {ATP }}$, although this hydrogen bond has only low probability in this model (Table S3). R603 is part of the shortest paths between nucleotide pockets in the $\mathrm{NC}^{\mathrm{ADP}}-\mathrm{CC}^{\mathrm{ATP}}$ and NC-CC models (Table 3). In the $\mathrm{NC}^{\mathrm{ADP}}-\mathrm{CC}^{\mathrm{ATP}}$ model, $\mathrm{R} 603$ is part of the shortest paths between almost each pair of active site residues analyzed (Table 3 ). $\mathrm{H} 1548$ is involved in all shortest paths in the NC-CC ${ }^{\mathrm{ATP}}$ model and in some shortest paths in the $\mathrm{NC}^{\text {ATP }}$ $\mathrm{CC}^{\text {ATP }}$ model (Table 3). These paths cross the interface between E602 and K1544 (Table S4). It is interesting to note that models with ATP bound to the $\mathrm{CC}$ show shortest paths crossing the interface at a similar location: models NC-CC ${ }^{\text {ATP }}$ and $\mathrm{NC}^{\mathrm{ADP}}$ $\mathrm{CC}^{\mathrm{ATP}}$ at E602 (to $\mathrm{K} 1544$ and subsequently to $\mathrm{H} 1548$ ) and model $\mathrm{NC}^{\mathrm{ADP}}-\mathrm{CC}^{\mathrm{ATP}}$ at the neighboring R603 (to L1540 or D1575; Table S4).

Together, these observations show that depending on the nucleotide occupation of the cassettes their inter-cassette contacts change, providing a molecular basis for the observation that mutations of residues at the cassette interface impact binding of ATP $\gamma \mathrm{S}$ to either cassette. The additional reduced ADP binding to both cassettes upon R603A mutation is furthermore reflected in the importance of R603 in shortest paths of the ADP-bound model NC ${ }^{\text {ADP }}$ CC $^{\text {ATP }}$ (Table 3).

\section{DISCUSSION}

Results presented here reveal intricate networks of intra-molecular communication in the Brr2 RNA helicase that modulate the adenine nucleotide binding specificities and affinities of the enzyme's $\mathrm{N}$ - and C-terminal nucleotide binding pockets. Changes at inter-cassette contacts or in a linker connecting the two cassettes affect nucleotide binding at both pockets. Furthermore, the Nterminal nucleotide binding pocket can "sense" nucleotide binding at the C-terminal pocket, i.e. over a distance of about $70 \AA$. Brr2 architecture and dynamics suggest likely molecular communication lines that mediate these long-range effects, which run through layers of structural elements in the vicinity of the nucleotide binding pockets, and which connect the two nucleotide binding pockets across the inter-cassette interface.

\section{Mechanism of nucleotide binding by Brr2}

To date, there are a limited number of reports on kinetic measurements of nucleotide binding to RNA and DNA helicases. To our knowledge, our work represents the first transient kinetics analysis of nucleotide binding to a double-cassette Ski2-like 
helicase. Due to the presence of two nucleotide binding pockets in Brr2, we initially characterized the kinetics of mant-ADP and mant-ATP $\gamma \mathrm{S}$ binding and dissociation using single cassette constructs, $\mathrm{hBrr} 2^{\mathrm{NC}}$ and $\mathrm{hBrr} 2^{\mathrm{CC}}$. Detailed characterization of the isolated cassettes allowed us to subsequently unequivocally assign double exponentials observed upon nucleotide binding or dissociation to/from dual-cassette constructs of $\mathrm{hBrr} 2$ to either of the cassettes.

Mant-nucleotide binding to hBrr2 generates FRET from NC and CC tryptophans to the mant moiety of the bound nucleotide. $\mathrm{hBrr} 2$ contains one and two trytophans within about $20 \AA$ distance of nucleotides bound at the $\mathrm{NC}$ and $\mathrm{CC}$, respectively (Fig. S1). The differences in the magnitudes of the FRET signals seen with mant-ADP or mantATP $\gamma$ S, with mant-ADP binding resulting in a higher amplitude compared to mant-ATP $\gamma \mathrm{S}$ binding (Fig. 2A,B), are explained by lower occupancy of the nucleotide binding pockets in the case of mant-ATP $\gamma \mathrm{S}$, due to a lower affinity of ATP $\gamma$ S compared to ADP (Table 1). Higher affinity for ADP is also reflected in the better defined electron densities for ADP/mant-ADP compared to $\mathrm{ATP} \gamma \mathrm{S} /$ mant-ATP $\gamma \mathrm{S}$ in the corresponding crystal structures (Fig. 3).

Nucleotide binding to other helicases such as Rep, DnaB and RecG showed multi-phasic kinetics, minimally characterized by a two-step mechanism, with a rapid nucleotide binding phase followed by nucleotide accommodation that resulted in a state of high nucleotide affinity characterized by high fluorescence (67-69). For $\mathrm{hBrr} 2$, both in the single-cassette as well as in the double-cassette constructs, nucleotide binding at both pockets could be modeled as a single-step, reversible process, as also observed for the DbpA helicase (70).

\section{Implications for the differential functions of the two helicase cassettes in Brr2}

Our results demonstrate that, in the absence of RNA, mant-ATP $\gamma \mathrm{S}$ binds more weakly to both cassettes than mant-ADP as also observed for the DEAD-box RNA helicase, DbpA (70). In addition, a comparison of the kinetics of nucleotide binding by the $\mathrm{hBrr} 2$ cassettes indicates that $\mathrm{hBrr} 2^{\mathrm{NC}}$ binds and releases nucleotides faster than $\mathrm{hBrr} 2^{\mathrm{CC}}$, both in isolation as well as in the dual-cassette constructs tested (Fig. 4 and 5). The high hBrr2 ${ }^{\mathrm{CC}}$ nucleotide affinity is the result of a very low nucleotide dissociation rate, with mant-ADP and mant-ATP $\gamma \mathrm{S}$ dissociation being 945 and 800 times slower for $\mathrm{hBrr} 2^{\mathrm{CC}}$ compared to $\mathrm{hBrr} 2^{\mathrm{NC}}$, respectively.

These results are consistent with the functions of the two cassettes for the activity of the enzyme. Fast nucleotide dynamics at the $\mathrm{NC}$ are in line with the $\mathrm{NC}$ being the active helicase cassette in the protein, which undergoes rounds of nucleotide binding, hydrolysis and release of the products, and which couples these transactions to conformational changes that give rise to translocation of the enzyme on the substrate RNA. The CC, in contrast, is inactive as an enzyme but stimulates the helicase activity of the NC (50). Rather than relying on conformational changes driven by nucleotide transactions, the $\mathrm{CC}$ may remain permanently bound to a nucleotide during Brr2-mediated RNA unwinding and provide a stable scaffold, which offers anchoring points for the NC, and can thereby support productive cycles of conformational changes in the NC. This picture is fully in line with our finding that mutations in inter-cassette contacts and in the inter-cassette linker, which would in part abrogate the ability of the NC to take advantage of the CC scaffold to transition between conformational states, influence nucleotide binding at the NC (Fig. 6). Furthermore, mutations in the $\mathrm{CC}$ nucleotide binding pocket designed to abrogate nucleotide binding also resulted in reduced nucleotide binding rates at the NC (Fig. 6).

Previously, mutations in the inter-cassette interface were seen to have only mild effects on the RNA-stimulated ATPase activity of hBrr2 (50). These observations could indicate that, in the presence of RNA, the impact of the mutations on nucleotide binding is not as pronounced as observed in our setup. However, some of the mutations still gave rise to significant defects in the RNA unwinding activity of the respective hBrr2 variants (50). Therefore, we expect that the mutations interfere with the coupling of the ATPase to the helicase activity in the NC.

\section{EXPERIMENTAL PROCEDURES \\ Cloning and mutagenesis}

Codon-optimized DNA fragments encoding $\mathrm{hBrr} 2^{\mathrm{FL}}$ (residues 1-2136) and fragments thereof $\left(\mathrm{hBrr} 2^{\mathrm{Tl}}\right.$ : residues 395-2129; $\mathrm{hBrr} 2^{\mathrm{NC}}$ : residues 395-1324; $\mathrm{hBrr} 2^{\mathrm{CC}}$ : residues 1282-2136) were cloned into a modified pFL vector (EMBL, 
Grenoble) to produce proteins with a TEVcleavable N-terminal His 10 -tag (50). Site-directed mutagenesis was performed using the QuikChange II XL Site-Directed Mutagenesis Kit (Stratagene). All constructs were verified by sequencing. All plasmids were transformed into Escherichia coli DH10MultiBacY cells (provided by Imre Berger, University of Bristol) and further integrated via Tn7 transposition into the baculovirus genome (EMBacY) maintained as a bacterial artificial chromosome (BAC) (71). The $\operatorname{Tn} 7$ transposition site was embedded in a lacZ $\alpha$ gene allowing the selection of positive EMBacY recombinants via blue/white screening. Recombinant BACs were isolated from the bacterial hosts and used to transfect Sf9 cells (Invitrogen).

\section{Protein production}

All proteins were produced by recombinant baculoviruses in insect cells, as described previously $(50,61)$. Briefly, for initial virus $\left(\mathrm{V}_{0}\right)$ production, the isolated recombinant EMBacY was transfected into adhesive Sf9 cells (Invitrogen) in 6-well plates. The efficiency of transfection was monitored by eYFP fluorescence. The $\mathrm{V}_{0}$ virus generation was used to infect $50 \mathrm{ml} \mathrm{Sf9}$ cells for virus amplification. The second, high titer virus generation $\left(V_{1}\right)$ was then used to infect $1200 \mathrm{ml}$ High Five ${ }^{\mathrm{TM}}$ cells (Invitrogen) for large scale protein production. The infected cells were harvested when the eYFP signal reached a plateau and before the cell viability dropped below $90 \%$.

\section{Protein purification}

Proteins were purified as described previously $(50,61)$. Briefly, for protein production for biochemical/biophysical experiments, the High Five $^{\mathrm{TM}}$ cell pellet was resuspended in $50 \mathrm{mM}$ HEPES-NaOH, pH 8.0, $600 \mathrm{mM} \mathrm{NaCl}, 2 \mathrm{mM} \beta-$ mercaptoethanol, $0.05 \% \mathrm{NP} 40,1.5 \mathrm{mM} \mathrm{MgCl}_{2}, 20$ (v/v) \% glycerol, $10 \mathrm{mM}$ imidazole, supplemented with EDTA-free protease inhibitor (Roche) and lyzed by sonication using a Sonopuls Ultrasonic Homogenizer HD 3100 (Bandelin). The target was captured from the cleared lysate on a $5 \mathrm{ml}$ HisTrap FF column (GE Healthcare) and eluted with a linear gradient from 10 to $250 \mathrm{mM}$ imidazole. The eluted protein containing the protein of interest was diluted to a final concentration of $80 \mathrm{mM} \mathrm{NaCl}$, treated with RNaseA (Sigma) and loaded on a Mono Q 10/100 GL column (GE Healthcare) equilibrated with $50 \mathrm{mM}$ Tris- $\mathrm{HCl}, \mathrm{pH} 8.0,50 \mathrm{mM}$ $\mathrm{NaCl}, 5$ (v/v) \% glycerol, $2 \mathrm{mM} \beta$-mercaptoethanol. The protein was eluted with a linear 0.05 to $1.5 \mathrm{M}$ $\mathrm{NaCl}$ gradient and further purified by gel filtration on a HiLoad Superdex 200 16/60 column (GE Healthcare) in $40 \mathrm{mM}$ Tris- $\mathrm{HCl}, \mathrm{pH} 8.0,200 \mathrm{mM}$ $\mathrm{NaCl}, 20$ (v/v) \% glycerol, $2 \mathrm{mM}$ DTT. The peak fractions were concentrated, flash-frozen in liquid nitrogen and stored at $-80{ }^{\circ} \mathrm{C}$.

For protein production for crystallization, the $\mathrm{hBrr} 2^{\mathrm{Tl}}$ insect cell pellet was lysed by sonification for $30 \mathrm{~min}$ in 50mM HEPES-NaOH $\mathrm{pH} 7.5$, $600 \mathrm{mM} \mathrm{NaCl}, 10 \%(\mathrm{w} / \mathrm{v})$ glycerol, $0.05 \%(\mathrm{v} / \mathrm{v})$ Nonidet P-40, 20 $\mu \mathrm{g} / \mathrm{ml}$ DNase I, 2mM $\beta$ mercaptoethanol, containing Complete EDTA-free protease inhibitors. After centrifugation and loading onto a HisTrap FF column, the protein was eluted with $250 \mathrm{mM}$ imidazole. TEV protease was added for cleavage of the His-tag, and the mixture was dialyzed overnight in $40 \mathrm{mM}$ HEPES-NaOH, $\mathrm{pH} 7.5,500 \mathrm{mM} \mathrm{NaCl}, 10 \%$ (w/v) glycerol, $15 \mathrm{mM}$ imidazole, $2 \mathrm{mM} \beta$-mercaptoethanol. The cleaved protein was collected in the flow-through of a HisTrap FF column. After five-fold dilution with $25 \mathrm{mM}$ Tris-HCl, $\mathrm{pH} 8.0,50 \mathrm{mM} \mathrm{NaCl}, 5 \%$ (v/v) glycerol, $2 \mathrm{mM}$ DTT and treatment with RNase A, the protein was loaded on a HiPrep Heparin FF column (GE Healthcare) equilibrated with $25 \mathrm{mM}$ Tris- $\mathrm{HCl}, \mathrm{pH} 8.0,50 \mathrm{mM} \mathrm{NaCl}, 5 \%$ (v/v) glycerol, $2 \mathrm{mM}$ DTT, and eluted by a linear increase of $\mathrm{NaCl}$ to $750 \mathrm{mM}$. The fractions of interest were combined and chromatographed on a HiLoad Superdex 200 $16 / 60$ column in $10 \mathrm{mM}$ Tris- $\mathrm{HCl}, \mathrm{pH} 7.5,200 \mathrm{mM}$ $\mathrm{NaCl}$, concentrated to $10 \mathrm{mg} / \mathrm{ml}$, flash-flozen in liquid nitrogen and stored at $-80{ }^{\circ} \mathrm{C}$.

The $\mathrm{hJab} 1^{\Delta \mathrm{C}}$ insect cell pellet was lysed by sonification for $30 \mathrm{~min}$ in $50 \mathrm{mM}$ Tris-HCl, $\mathrm{pH} 8.0$, $300 \mathrm{mM} \mathrm{NaCl}, 5 \%$ (v/v) glycerol, $0.05 \%$ (v/v) NP40, 2 mM DTT, supplemented with Complete EDTA-free protease inhibitors. After centrifugation, the protein was captured on glutathione sepharose beads (GE Healthcare) and eluted with $10 \mathrm{mM}$ reduced glutathione. Buffer was exchanged to $50 \mathrm{mM}$ Tris- $\mathrm{HCl}, \mathrm{pH} 8.0,300 \mathrm{mM}$ $\mathrm{NaCl}, 5 \%$ (v/v) glycerol, $2 \mathrm{mM}$ DTT on a HiLoad Superdex 75 26/60 column (GE Healthcare). After treatment with Prescission protease overnight, the hJab1 ${ }^{\Delta \mathrm{C}}$ protein lacking the GST tag was collected in the flow-through of glutathione sepharose beads. Subsequently, the protein was loaded on a HiLoad Superdex 75 16/60 column in $10 \mathrm{mM}$ Tris-HCl, pH 
Long-range allosteric effects in an RNA helicase

8.0, $150 \mathrm{mM} \mathrm{NaCl}$, concentrated to $4 \mathrm{mg} / \mathrm{ml}$, flashflozen in liquid nitrogen and stored at $-80{ }^{\circ} \mathrm{C}$.

For complex formation, hBrr2 ${ }^{\mathrm{T} 1}$ was combined with a 1.5 -fold molar excess of $\mathrm{hJab} 1^{\Delta \mathrm{C}}$, and the complex was purified by gel filtration on a Superdex 200 10/300 global increase column (GE Healthcare) in $20 \mathrm{mM}$ Tris- $\mathrm{HCl}, \mathrm{pH} 8.0,150 \mathrm{mM}$ $\mathrm{NaCl}$, concentrated to $6 \mathrm{mg} / \mathrm{ml}$, flash-frozen in liquid nitrogen and stored at $-80^{\circ} \mathrm{C}$.

\section{Crystallographic analyses}

Crystals of the $\mathrm{hBrr} 2^{\mathrm{T} 1}-\mathrm{hJ} a b 1^{\Delta \mathrm{C}}$ complex were grown in a 24-well plate with a reservoir solution of $0.1 \mathrm{M}$ HEPES-NaOH, $\mathrm{pH} 8.0,0.1 \mathrm{M} \mathrm{MgCl}_{2}, 8 \%$ PEG 3350, as described before (61). Crystals were soaked for $1 \mathrm{~h}$ in $10 \mathrm{mM}$ ADP or ATP $\gamma \mathrm{S}$, or in 1 $\mathrm{mM}$ mant-ADP or mant-ATP $\gamma \mathrm{S}$ (Jena Bioscience) in reservoir solution. After cryoprotection with 25 $\%$ (v/v) ethylene glycol in reservoir solution, crystals were flash-cooled in liquid nitrogen.

Diffraction data were acquired at beamline 14.2 of the BESSY II storage ring (Berlin, Germany) and processed with XDS (72). Molecular replacement was done with Phenix (73) using the structure coordinates of the $\mathrm{hBrr} 2^{\mathrm{T} 1}-\mathrm{hJab} 1^{\Delta \mathrm{C}}$ complex (PDB ID 6S8Q) (61). The structures were manually adjusted with Coot (74) and automatically refined with Phenix. Restraints for the ligands were generated by the "eLBOW"-tool of Phenix. Structure figures were prepared with PyMOL (Version 1.8 Schrödinger, LLC).

\section{Characterization of protein variants}

DSF experiments were done in a 96-well plate in a plate reader combined with a thermocycler (Stratagene Mx3005P). All hBrr2 constructs were diluted to a final concentration of $3 \mu \mathrm{M}$ in

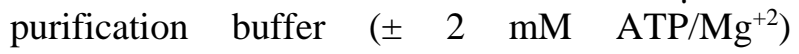
supplemented with $10 \times \mathrm{SYPRO}$ orange (1:500 dilution of the stock) in a total volume of $20 \mu \mathrm{l}$. The temperature was increased linearly from $25{ }^{\circ} \mathrm{C}$ to $95^{\circ} \mathrm{C}$ and the fluorescence emission was monitored in steps of $1{ }^{\circ} \mathrm{C} / \mathrm{min}$ with hold steps of $30 \mathrm{~s}$ between reads. The fluorescence intensity was then plotted as a function of temperature. The sigmoidal curve from each construct was normalized and corrected for the background signal of the fluorophore in the buffer. The inflection points of the curves, representing the thermal melting temperature, were extracted from the first derivatives of the melting profiles using OriginLab.

\section{Rapid kinetic measurements}

The kinetics of the interaction of hBrr2 variants with nucleotides were characterized via fluorescence stopped-flow measurements on an SX-20MV spectrometer (Applied Photophysics). The fluorescence of mant-labeled nucleotides was excited using $290 \mathrm{~nm}$ light via FRET from tryptophan residues in the proximity of the nucleotide binding pockets and measured at $90^{\circ}$ after passing a cut-off filter (KV 408, Schott). FRET was observed only when both donor and acceptor were present since a negligible fluorescence change of tryptophan was observed when non-fluorescent nucleotides were bound to the proteins. Association experiments were performed by rapidly mixing equal volumes $(60 \mu \mathrm{l})$ of the reactants (syringe 1 contained hBrr2 variants while syringe 2 contained the mant nucleotides) in $20 \mathrm{mM}$ HEPES-NaOH, pH 8.0, $150 \mathrm{mM} \mathrm{NaCl}, 1.5$ $\mathrm{mM} \mathrm{MgCl} 2$ at $20{ }^{\circ} \mathrm{C}$ and monitoring fluorescence change over time. Dissociation or chase experiments were performed similarly by rapidly mixing equal volumes $(60 \mu \mathrm{l})$ of the reactants (syringe 1 contained hBrr2 variants in complex with mant nucleotides while syringe 2 contained an excess of unlabeled nucleotides) at $20{ }^{\circ} \mathrm{C}$ and monitoring fluorescence change over time. In all cases, 1000 data points were acquired in logarithmic sampling mode. The data were visualized using the Pro-Data Viewer software package (Applied Photophysics). The final curves were obtained by averaging 7-10 individual traces after normalizing each data point to initial $F_{0}$. Data were evaluated by fitting to a single exponential function with a characteristic time constant $\left(k_{a p p}\right)$, amplitude $\left(F_{1}\right)$ and another variable for the final signal $\left(F_{\infty}\right)$ according to the equation, $F=F_{\infty}+$ $F_{l} \exp \left(-k_{a p p} \mathrm{t}\right)$, in which $F$ is the fluorescence at time $t$. For constructs containing two nucleotide binding sites, two exponential terms were used with two characteristic time constants ( $\left.k_{a p p l}, k_{a p p 2}\right)$, amplitudes of the signal change $\left(F_{1}, F_{2}\right)$ and another variable for the final signal $\left(F_{\infty}\right)$ according to the equation, $F=F_{\infty}+F_{l} \exp \left(-k_{a p p} t\right)+F_{2} \exp \left(-k_{a p p 2} \mathrm{t}\right)$. Dependencies of the apparent rate constants on nucleotide concentration were fitted by a linear equation, $k_{a p p}=k_{l}$ [mant-nucleotide] $+k_{-l}$, in which $k_{1}$ represents the nucleotide association rate constant (derived from the slope), and $k_{-l}$ represents the nucleotide dissociation rate constant (derived 
from the $\mathrm{Y}$-axis intercept). Calculations and statistical analysis were performed using Prism software (GraphPad).

\section{Molecular dynamics simulations}

$\mathrm{hBrr} 2^{403}$ to 2125 was modeled based on PDB entries 4F91 (for the apo form) and 4F93 (for nucleotide-bound forms) (50). ADP was changed in silico to ATP and one magnesium ion was modeled into the NC binding pocket using its position relative to ATP in the CC pocket as a template. Protein, nucleotides and ions were described with the CHARMM force field (75). The (nucleotidebound) proteins were first relaxed by 500 steps of steepest descend. The relaxed structures were then solvated by TIP3P water (76) in a dodecahedral box, extending $1.5 \mathrm{~nm}$ from the solute $(\sim 1.8 \mathrm{~nm}$ length). After 5000 steps of optimization, keeping the nucleotide fixed, $1 \mathrm{~ns}$ of molecular dynamics simulations with all protein heavy atoms positionally restrained were performed to further equilibrate the systems at $300 \mathrm{~K}$, using a Berendsen thermostat (77). Finally, molecular dynamics production runs of $200 \mathrm{~ns}$ length were performed in an NVT ensemble, at $300 \mathrm{~K}$ controlling temperature by canonical sampling through canonical velocityrescaling (78), and 2 fs time steps for the integration with the LINCS algorithm (79) to constrain covalent bonds. Electrostatic interactions were treated with the particle mesh Ewald method (80) on a grid with 0.16 spacing and a short-range cutoff of $1.4 \mathrm{~nm}$. The same cut-off was applied to the van der Waals interactions. All simulations were performed with Gromacs 4.6.7 (81).

For the analyses, only the last $100 \mathrm{~ns}$ simulation time were considered. Hydrogen bonds were defined geometrically by a $3.2 \AA$ maximal distance between donor (D) and acceptor (A) atoms and 42 - maximum deviation from linearity for the D$\mathrm{H} \cdot \mathrm{A}$ A angle.

For the communication analysis, a weighted graph was constructed, in which the protein residues form the nodes, and edges between nodes were defined by the occurrence of a hydrogen bond in the course of the simulation. The probabilities of these hydrogen bonds to occur served as edge weights. The probability of hydrogen bonds between two residues $\mathrm{i}$ and $\mathrm{j}, \mathrm{HB}_{\mathrm{ij}}$, were converted into communication costs $\mathrm{C}_{\mathrm{ij}}=-\ln \left(\mathrm{HB}_{\mathrm{ij}}\right)$. Consecutive residues, i.e. covalently bound, were assigned a communication cost of zero. Shortest paths were selected from the resulting communication graph using Dijkstra's algorithm (82), with the path lengths taken as the sum of the edge weights along the path. The analysis of hydrogen bonds, setup and evaluation of communication graphs were carried out using our own Java code, based on the Jgraph library (83).

Protein flexibilities were analyzed using the rmsf tool of the Gromacs program. Errors were estimated from block averaging, partitioning the last $100 \mathrm{~ns}$ of the simulation data into to five blocks of 20ns length each. 


\section{Acknowledgments:}

We thank Imre Berger, University of Bristol, for E. coli DH10MultiBacY cells. We acknowledge access to beamlines BL14.1/2/3 of the BESSY II storage ring (Berlin, Germany) via the Joint Berlin MXLaboratory sponsored by the Helmholtz-Zentrum Berlin für Materialien und Energie, Freie Universität Berlin, Humboldt-Universität zu Berlin, the Max-Delbrück Centrum für Molekular Medizin, the LeibnizForschungsinstitut für Molekulare Pharmakologie and Charité - Universitätsmedizin Berlin. We are grateful for Computational resources provided by the North-German Supercomputing Alliance (HLRN). This work was funded by grant TRR186/A15 from the Deutsche Forschungsgemeinschaft to MCW. KFS was supported by a Dahlem International Network PostDoc Fellowship from Freie Universität Berlin.

\section{Conflict of interests:}

The authors declare no conflict of interest. 
Long-range allosteric effects in an RNA helicase

\section{REFERENCES}

1. Johnson, S. J., and Jackson, R. N. (2013) Ski2-like RNA helicase structures: common themes and complex assemblies. RNA Biol. 10, 33-43

2. Walbott, H., Mouffok, S., Capeyrou, R., Lebaron, S., Humbert, O., van Tilbeurgh, H., Henry, Y., and Leulliot, N. (2010) Prp43p contains a processive helicase structural architecture with a specific regulatory domain. EMBO J. 29, 2194-2204

3. Kudlinzki, D., Schmitt, A., Christian, H., and Ficner, R. (2012) Structural analysis of the C-terminal domain of the spliceosomal helicase Prp22. Biol Chem 393, 1131-1140

4. He, Y., Andersen, G. R., and Nielsen, K. H. (2010) Structural basis for the function of DEAH helicases. EMBO Rep. 11, 180-186

5. Absmeier, E., Becke, C., Wollenhaupt, J., Santos, K. F., and Wahl, M. C. (2017) Interplay of cis- and trans-regulatory mechanisms in the spliceosomal RNA helicase Brr2. Cell Cycle 16, 100-112

6. Fairman-Williams, M. E., Guenther, U. P., and Jankowsky, E. (2010) SF1 and SF2 helicases: family matters. Curr Opin Struct Biol 20, 313-324

7. Weir, J. R., Bonneau, F., Hentschel, J., and Conti, E. (2010) Structural analysis reveals the characteristic features of Mtr4, a DExH helicase involved in nuclear RNA processing and surveillance. Proc. Natl. Acad. Sci. USA 107, 12139-12144

8. Büttner, K., Nehring, S., and Hopfner, K. P. (2007) Structural basis for DNA duplex separation by a superfamily-2 helicase. Nat. Struct. Mol. Biol. 14, 647-652

9. Oyama, T., Oka, H., Mayanagi, K., Shirai, T., Matoba, K., Fujikane, R., Ishino, Y., and Morikawa, K. (2009) Atomic structures and functional implications of the archaeal RecQ-like helicase Hjm. BMC Struct. Biol. 9, 2

10. Pyle, A. M. (2008) Translocation and unwinding mechanisms of RNA and DNA helicases. Annu. Rev. Biophys. 37, 317-336

11. Tanner, N. K., Cordin, O., Banroques, J., Doere, M., and Linder, P. (2003) The Q motif: A newly identified motif in DEAD box helicases may regulate ATP binding and hydrolysis. Mol. Cell 11, 127138

12. Halbach, F., Rode, M., and Conti, E. (2012) The crystal structure of S. cerevisiae Ski2, a DExH helicase associated with the cytoplasmic functions of the exosome. RNA 18, 124-134

13. Searfoss, A., Dever, T. E., and Wickner, R. (2001) Linking the 3 ' poly(A) tail to the subunit joining step of translation initiation: relations of Pablp, eukaryotic translation initiation factor $5 \mathrm{~b}$ (Fun12p), and Ski2p-Slh1p. Mol Cell Biol 21, 4900-4908

14. Raghunathan, P. L., and Guthrie, C. (1998) RNA unwinding in U4/U6 snRNPs requires ATP hydrolysis and the DEIH-box splicing factor Brr2. Curr. Biol. 8, 847-855

15. Conrad, K. S., Hurley, J. M., Widom, J., Ringelberg, C. S., Loros, J. J., Dunlap, J. C., and Crane, B. R. (2016) Structure of the frequency-interacting RNA helicase: a protein interaction hub for the circadian clock. EMBO J. 35, 1707-1719

16. Tanaka, K., Miyamoto, N., Shouguchi-Miyata, J., and Ikeda, J. E. (2006) HFM1, the human homologue of yeast Mer3, encodes a putative DNA helicase expressed specifically in germ-line cells. DNA Seq 17, 242-246

17. Guiraldelli, M. F., Eyster, C., Wilkerson, J. L., Dresser, M. E., and Pezza, R. J. (2013) Mouse HFM1/Mer3 is required for crossover formation and complete synapsis of homologous chromosomes during meiosis. PLoS Genet 9 , e1003383

18. Guy, C. P., and Bolt, E. L. (2005) Archaeal Hel308 helicase targets replication forks in vivo and in vitro and unwinds lagging strands. Nucleic Acids Res. 33, 3678-3690

19. Jung, D. J., Sung, H. S., Goo, Y. W., Lee, H. M., Park, O. K., Jung, S. Y., Lim, J., Kim, H. J., Lee, S. K., Kim, T. S., Lee, J. W., and Lee, Y. C. (2002) Novel transcription coactivator complex containing activating signal cointegrator 1 . Mol Cell Biol 22, 5203-5211

20. Dango, S., Mosammaparast, N., Sowa, M. E., Xiong, L. J., Wu, F., Park, K., Rubin, M., Gygi, S., Harper, J. W., and Shi, Y. (2011) DNA unwinding by ASCC3 helicase is coupled to ALKBH3dependent DNA alkylation repair and cancer cell proliferation. Mol. Cell 44, 373-384 
21. Matsuo, Y., Ikeuchi, K., Saeki, Y., Iwasaki, S., Schmidt, C., Udagawa, T., Sato, F., Tsuchiya, H., Becker, T., Tanaka, K., Ingolia, N. T., Beckmann, R., and Inada, T. (2017) Ubiquitination of stalled ribosome triggers ribosome-associated quality control. Nat Commun 8, 159

22. Hashimoto, S., Sugiyama, T., Yamazaki, R., Nobuta, R., and Inada, T. (2020) Identification of a novel trigger complex that facilitates ribosome-associated quality control in mammalian cells. Sci. Rep. 10, 3422

23. Juszkiewicz, S., Speldewinde, S. H., Wan, L., Svejstrup, J. Q., and Hegde, R. S. (2020) The ASC-1 Complex Disassembles Collided Ribosomes. Mol. Cell 79, 603-614 e608

24. Sugiyama, T., Li, S., Kato, M., Ikeuchi, K., Ichimura, A., Matsuo, Y., and Inada, T. (2019) Sequential Ubiquitination of Ribosomal Protein uS3 Triggers the Degradation of Non-functional 18S rRNA. Cell Rep 26, 3400-3415 e3407

25. Li, J., Ding, S. C., Cho, H., Chung, B. C., Gale, M., Jr., Chanda, S. K., and Diamond, M. S. (2013) A short hairpin RNA screen of interferon-stimulated genes identifies a novel negative regulator of the cellular antiviral response. MBio 4, e00385-00313

26. Mazina, O. M., Mazin, A. V., Nakagawa, T., Kolodner, R. D., and Kowalczykowski, S. C. (2004) Saccharomyces cerevisiae Mer3 helicase stimulates 3'-5' heteroduplex extension by Rad51; implications for crossover control in meiotic recombination. Cell 117, 47-56

27. Bernstein, J., Patterson, D. N., Wilson, G. M., and Toth, E. A. (2008) Characterization of the essential activities of Saccharomyces cerevisiae Mtr4p, a 3'->5' helicase partner of the nuclear exosome. J. Biol. Chem. 283, 4930-4942

28. Mozaffari-Jovin, S., Santos, K. F., Hsiao, H. H., Will, C. L., Urlaub, H., Wahl, M. C., and Lührmann, R. (2012) The Prp8 RNase H-like domain inhibits Brr2-mediated U4/U6 snRNA unwinding by blocking Brr2 loading onto the U4 snRNA. Genes Dev. 26, 2422-2434

29. Nguyen, T. H., Galej, W. P., Bai, X. C., Savva, C. G., Newman, A. J., Scheres, S. H., and Nagai, K. (2015) The architecture of the spliceosomal U4/U6.U5 tri-snRNP. Nature 523, 47-52

30. Lauber, J., Fabrizio, P., Teigelkamp, S., Lane, W. S., Hartmann, E., and Luhrmann, R. (1996) The HeLa $200 \mathrm{kDa}$ U5 snRNP-specific protein and its homologue in Saccharomyces cerevisiae are members of the DEXH-box protein family of putative RNA helicases. EMBO J. 15, 4001-4015.

31. Noble, S. M., and Guthrie, C. (1996) Transcriptional pulse-chase analysis reveals a role for a novel snRNP- associated protein in the manufacture of spliceosomal snRNPs. EMBO J. 15, 4368-4379

32. Bessonov, S., Anokhina, M., Will, C. L., Urlaub, H., and Lührmann, R. (2008) Isolation of an active step I spliceosome and composition of its RNP core. Nature 452, 846-850

33. Deckert, J., Hartmuth, K., Boehringer, D., Behzadnia, N., Will, C. L., Kastner, B., Stark, H., Urlaub, H., and Lührmann, R. (2006) Protein composition and electron microscopy structure of affinitypurified human spliceosomal B complexes isolated under physiological conditions. Mol Cell Biol 26, 5528-5543

34. Fabrizio, P., Dannenberg, J., Dube, P., Kastner, B., Stark, H., Urlaub, H., and Lührmann, R. (2009) The evolutionarily conserved core design of the catalytic activation step of the yeast spliceosome. Mol. Cell 36, 593-608

35. Xu, D., Nouraini, S., Field, D., Tang, S. J., and Friesen, J. D. (1996) An RNA-dependent ATPase associated with U2/U6 snRNAs in pre-mRNA splicing. Nature 381, 709-713

36. Zhang, L., Li, X., Hill, R. C., Qiu, Y., Zhang, W., Hansen, K. C., and Zhao, R. (2015) Brr2 plays a role in spliceosomal activation in addition to U4/U6 unwinding. Nucleic Acids Res. 43, 3286-3297

37. Laggerbauer, B., Achsel, T., and Lührmann, R. (1998) The human U5-200kD DEXH-box protein unwinds U4/U6 RNA duplices in vitro. Proc. Natl. Acad. Sci. USA 95, 4188-4192

38. Nguyen, T. H., Galej, W. P., Bai, X. C., Oubridge, C., Newman, A. J., Scheres, S. H., and Nagai, K. (2016) Cryo-EM structure of the yeast U4/U6.U5 tri-snRNP at 3.7 A resolution. Nature 530, 298-302

39. Agafonov, D. E., Deckert, J., Wolf, E., Odenwalder, P., Bessonov, S., Will, C. L., Urlaub, H., and Luhrmann, R. (2011) Semiquantitative proteomic analysis of the human spliceosome via a novel twodimensional gel electrophoresis method. Mol Cell Biol 31, 2667-2682 
40. Yan, C., Wan, R., Bai, R., Huang, G., and Shi, Y. (2016) Structure of a yeast activated spliceosome at 3.5 A resolution. Science $353,904-911$

41. Galej, W. P., Wilkinson, M. E., Fica, S. M., Oubridge, C., Newman, A. J., and Nagai, K. (2016) CryoEM structure of the spliceosome immediately after branching. Nature 537, 197-201

42. Chen, H. C., Tseng, C. K., Tsai, R. T., Chung, C. S., and Cheng, S. C. (2013) Link of NTR-mediated spliceosome disassembly with DEAH-box ATPases Prp2, Prp16, and Prp22. Mol Cell Biol 33, 514525

43. Fourmann, J. B., Schmitzova, J., Christian, H., Urlaub, H., Ficner, R., Boon, K. L., Fabrizio, P., and Lührmann, R. (2013) Dissection of the factor requirements for spliceosome disassembly and the elucidation of its dissociation products using a purified splicing system. Genes Dev. 27, 413-428

44. Tsai, R. T., Tseng, C. K., Lee, P. J., Chen, H. C., Fu, R. H., Chang, K. J., Yeh, F. L., and Cheng, S. C. (2007) Dynamic interactions of Ntr1-Ntr2 with Prp43 and with U5 govern the recruitment of Prp43 to mediate spliceosome disassembly. Mol Cell Biol 27, 8027-8037

45. Hahn, D., Kudla, G., Tollervey, D., and Beggs, J. D. (2012) Brr2p-mediated conformational rearrangements in the spliceosome during activation and substrate repositioning. Genes Dev. 26, 24082421

46. Mayerle, M., and Guthrie, C. (2016) Prp8 retinitis pigmentosa mutants cause defects in the transition between the catalytic steps of splicing. RNA 22, 793-809

47. Small, E. C., Leggett, S. R., Winans, A. A., and Staley, J. P. (2006) The EF-G-like GTPase Snu114p regulates spliceosome dynamics mediated by Brr2p, a DExD/H box ATPase. Mol. Cell 23, 389-399

48. Pena, V., Mozaffari-Jovin, S., Fabrizio, P., Orlowski, J., Bujnicki, J. M., Lührmann, R., and Wahl, M. C. (2009) Common design principles in the spliceosomal RNA helicase Brr2 and in the Hel308 DNA helicase. Mol. Cell 35, 454-466

49. Zhang, L., Xu, T., Maeder, C., Bud, L. O., Shanks, J., Nix, J., Guthrie, C., Pleiss, J. A., and Zhao, R. (2009) Structural evidence for consecutive Hel308-like modules in the spliceosomal ATPase Brr2. Nat. Struct. Mol. Biol. 16, 731-739

50. Santos, K. F., Mozaffari-Jovin, S., Weber, G., Pena, V., Lührmann, R., and Wahl, M. C. (2012) Structural basis for functional cooperation between tandem helicase cassettes in Brr2-mediated remodeling of the spliceosome. Proc. Natl. Acad. Sci. USA 109, 17418-17423

51. Martegani, E., Vanoni, M., Mauri, I., Rudoni, S., Saliola, M., and Alberghina, L. (1997) Identification of gene encoding a putative RNA-helicase, homologous to SKI2, in chromosome VII of Saccharomyces cerevisiae. Yeast 13, 391-397

52. Kim, D. H., and Rossi, J. J. (1999) The first ATPase domain of the yeast 246-kDa protein is required for in vivo unwinding of the U4/U6 duplex. RNA 5, 959-971

53. Liu, S., Rauhut, R., Vornlocher, H. P., and Lührmann, R. (2006) The network of protein-protein interactions within the human U4/U6.U5 tri-snRNP. RNA 12, 1418-1430

54. van Nues, R. W., and Beggs, J. D. (2001) Functional contacts with a range of splicing proteins suggest a central role for Brr2p in the dynamic control of the order of events in spliceosomes of Saccharomyces cerevisiae. Genetics 157, 1451-1467

55. Mozaffari-Jovin, S., Wandersleben, T., Santos, K. F., Will, C. L., Lührmann, R., and Wahl, M. C. (2013) Inhibition of RNA helicase Brr2 by the C-terminal tail of the spliceosomal protein Prp8. Science 341, 80-84

56. Absmeier, E., Wollenhaupt, J., Mozaffari-Jovin, S., Becke, C., Lee, C. T., Preussner, M., Heyd, F., Urlaub, H., Luhrmann, R., Santos, K. F., and Wahl, M. C. (2015) The large N-terminal region of the Brr2 RNA helicase guides productive spliceosome activation. Genes Dev. 29, 2576-2587

57. Huang, Y. H., Chung, C. S., Kao, D. I., Kao, T. C., and Cheng, S. C. (2014) Sad1 Counteracts Brr2Mediated Dissociation of U4/U6.U5 in Tri-snRNP Homeostasis. Mol Cell Biol 34, 210-220

58. Absmeier, E., Rosenberger, L., Apelt, L., Becke, C., Santos, K. F., Stelzl, U., and Wahl, M. C. (2015) A noncanonical PWI domain in the N-terminal helicase-associated region of the spliceosomal Brr2 protein. Acta Crystallogr. D 71, 762-771 
59. Nguyen, T. H., Li, J., Galej, W. P., Oshikane, H., Newman, A. J., and Nagai, K. (2013) Structural basis of Brr2-Prp8 interactions and implications for U5 snRNP biogenesis and the spliceosome active site. Structure 21, 910-919

60. O'Brien, E. T., and Erickson, H. P. (1989) Assembly of pure tubulin in the absence of free GTP: effect of magnesium, glycerol, ATP, and the nonhydrolyzable GTP analogues. Biochemistry 28, 1413-1422

61. Vester, K., Santos, K. F., Kuropka, B., Weise, C., and Wahl, M. C. (2020) The inactive C-terminal cassette of the dual-cassette RNA helicase BRR2 both stimulates and inhibits the activity of the Nterminal helicase unit. J. Biol. Chem. 295, 2097-2112

62. Gromadski, K. B., Wieden, H. J., and Rodnina, M. V. (2002) Kinetic mechanism of elongation factor Ts-catalyzed nucleotide exchange in elongation factor Tu. Biochemistry 41, 162-169

63. Milon, P., Tischenko, E., Tomsic, J., Caserta, E., Folkers, G., La Teana, A., Rodnina, M. V., Pon, C. L., Boelens, R., and Gualerzi, C. O. (2006) The nucleotide-binding site of bacterial translation initiation factor 2 (IF2) as a metabolic sensor. Proc. Natl. Acad. Sci. USA 103, 13962-13967

64. Milon, P., Konevega, A. L., Peske, F., Fabbretti, A., Gualerzi, C. O., and Rodnina, M. V. (2007) Transient kinetics, fluorescence, and FRET in studies of initiation of translation in bacteria. Methods Enzymol. 430, 1-30

65. Goyal, A., Belardinelli, R., Maracci, C., Milon, P., and Rodnina, M. V. (2015) Directional transition from initiation to elongation in bacterial translation. Nucleic Acids Res. 43, 10700-10712

66. Walker, J. E., Saraste, M., Runswick, M. J., and Gay, N. J. (1982) Distantly related sequences in the alpha- and beta-subunits of ATP synthase, myosin, kinases and other ATP-requiring enzymes and a common nucleotide binding fold. EMBO J. 1, 945-951

67. Moore, K. J., and Lohman, T. M. (1994) Kinetic mechanism of adenine nucleotide binding to and hydrolysis by the Escherichia coli Rep monomer. 2. Application of a kinetic competition approach. Biochemistry 33, 14565-14578

68. Bujalowski, W., and Jezewska, M. J. (2000) Kinetic mechanism of nucleotide cofactor binding to Escherichia coli replicative helicase DnaB protein. stopped-flow kinetic studies using fluorescent, ribose-, and base-modified nucleotide analogues. Biochemistry 39, 2106-2122

69. Toseland, C. P., Powell, B., and Webb, M. R. (2012) ATPase cycle and DNA unwinding kinetics of RecG helicase. PLoS One 7, e38270

70. Talavera, M. A., and De La Cruz, E. M. (2005) Equilibrium and kinetic analysis of nucleotide binding to the DEAD-box RNA helicase DbpA. Biochemistry 44, 959-970

71. Trowitzsch, S., Bieniossek, C., Nie, Y., Garzoni, F., and Berger, I. (2010) New baculovirus expression tools for recombinant protein complex production. J. Struct. Biol. 172, 45-54

72. Kabsch, W. (2010) XDS. Acta Crystallogr. D 66, 125-132

73. Adams, P. D., Grosse-Kunstleve, R. W., Hung, L. W., Ioerger, T. R., McCoy, A. J., Moriarty, N. W., Read, R. J., Sacchettini, J. C., Sauter, N. K., and Terwilliger, T. C. (2002) PHENIX: building new software for automated crystallographic structure determination. Acta Crystallogr. D 58, 1948-1954

74. Emsley, P., Lohkamp, B., Scott, W. G., and Cowtan, K. (2010) Features and development of Coot. Acta Crystallogr. D 66, 486-501

75. Brooks, B. R., Brooks, C. L., 3rd, Mackerell, A. D., Jr., Nilsson, L., Petrella, R. J., Roux, B., Won, Y., Archontis, G., Bartels, C., Boresch, S., Caflisch, A., Caves, L., Cui, Q., Dinner, A. R., Feig, M., Fischer, S., Gao, J., Hodoscek, M., Im, W., Kuczera, K., Lazaridis, T., Ma, J., Ovchinnikov, V., Paci, E., Pastor, R. W., Post, C. B., Pu, J. Z., Schaefer, M., Tidor, B., Venable, R. M., Woodcock, H. L., Wu, X., Yang, W., York, D. M., and Karplus, M. (2009) CHARMM: the biomolecular simulation program. J Comput Chem 30, 1545-1614

76. Price, D. J., and Brooks, C. L., 3rd. (2004) A modified TIP3P water potential for simulation with Ewald summation. J Chem Phys 121, 10096-10103

77. Khalili, M., Liwo, A., Jagielska, A., and Scheraga, H. A. (2005) Molecular dynamics with the unitedresidue model of polypeptide chains. II. Langevin and Berendsen-bath dynamics and tests on model alpha-helical systems. The journal of physical chemistry. B 109, 13798-13810 
78. Bussi, G., Donadio, D., and Parrinello, M. (2007) Canonical sampling through velocity rescaling. $J$ Chem Phys 126, 014101

79. Hess, B. (2008) P-LINCS: A Parallel Linear Constraint Solver for Molecular Simulation. J Chem Theory Comput 4, 116-122

80. Abraham, M. J., and Gready, J. E. (2011) Optimization of parameters for molecular dynamics simulation using smooth particle-mesh Ewald in GROMACS 4.5. J Comput Chem 32, 2031-2040

81. Van Der Spoel, D., Lindahl, E., Hess, B., Groenhof, G., Mark, A. E., and Berendsen, H. J. (2005) GROMACS: fast, flexible, and free. J Comput Chem 26, 1701-1718

82. Dijkstra, E. W. (1959) A note on two problems in connexion with graphs. Num Mathematik 1, 269271

83. Bagga, J., and Heinz, A. (2002) JGraph - A Java based system for drawing graphs and running graph algorithms. Lect Notes Comput Sc 2265, 459-460

84. Karplus, P. A., and Diederichs, K. (2015) Assessing and maximizing data quality in macromolecular crystallography. Curr Opin Struct Biol 34, 60-68 


\section{Footnotes}

This work was funded by grant TRR186/A15 from the Deutsche Forschungsgemeinschaft to MCW. KFS was supported by a Dahlem International Network PostDoc Fellowship from Freie Universität Berlin.

The abbreviations used are: BAC, bacterial artificial chromosome; CC, C-terminal cassette; DSF, differential scanning fluorimetry; DTT, dithiothreitol; FRET, fluorescence resonance energy transfer; h, human; HB, helical bundle domain; HLH, helix-loop-helix domain; IG, immunoglobulin-like domain; mant, methylanthraniloyl; MD, molecular dynamics; NC, N-terminal cassette; NTR, N-terminal region; NTPase, nucleic acid-dependent nucleotide tri-phosphatase; pre-mRNA, precursor messenger RNA; RNP, ribonucleoprotein complex; SEM, standard error of the mean; SF2, superfamily 2; sn, small nuclear; ss, single-stranded; T1, truncation 1; Tris, tris(hydroxymethyl)aminomethane; v/v, volume/volume; WH, winged-helix domain; wt, wild type. 
bioRxiv preprint doi: https://doi.org/10.1101/2021.01.28.428616; this version posted January 30,2021 . The copyright holder for this preprint (which was not certified by peer review) is the author/funder, who has granted bioRxiv a license to display the preprint in perpetuity. It is made available under aCC-BY-NC-ND 4.0 International license.

Long-range allosteric effects in an RNA helicase

\section{TABLES}

Table 1. Kinetics of nucleotide binding and release.

\begin{tabular}{|c|c|c|c|c|c|c|c|c|c|}
\hline \multirow{3}{*}{ Protein } & \multirow{3}{*}{$\begin{array}{c}\text { Data } \\
\text { fitting }\end{array}$} & \multicolumn{4}{|c|}{ mant-ADP } & \multicolumn{4}{|c|}{ mant-ATP $\gamma \mathrm{S}$} \\
\hline & & \multicolumn{2}{|c|}{$\mathrm{NC}$} & \multicolumn{2}{|c|}{$\mathrm{CC}$} & \multicolumn{2}{|c|}{$\mathrm{NC}$} & \multicolumn{2}{|c|}{$\mathrm{CC}$} \\
\hline & & $\begin{array}{c}k_{1} \\
{\left[\mu M^{-1} \mathbf{s}^{-1}\right]}\end{array}$ & $\begin{array}{c}k_{-1} \\
{\left[\mathrm{~s}^{-1}\right]}\end{array}$ & $\begin{array}{c}k_{1} \\
{\left[\mu M^{-1} \mathbf{s}^{-1}\right]}\end{array}$ & $\begin{array}{c}k_{-1} \\
10^{-3}\left[\mathrm{~s}^{-1}\right]\end{array}$ & $\begin{array}{c}k_{1} \\
{\left[\mu M^{-1} \mathbf{s}^{-1}\right]}\end{array}$ & $\begin{array}{c}k_{-1} \\
{\left[\mathrm{~s}^{-1}\right]}\end{array}$ & $\begin{array}{c}k_{l} \\
{\left[\mu M^{-1} \mathbf{s}^{-1}\right]}\end{array}$ & $\begin{array}{c}k_{-1} 10^{-3} \\
{\left[\mathrm{~s}^{-1}\right]}\end{array}$ \\
\hline hBrr2 $2^{\mathrm{NC}}$ & SE & $\begin{array}{c}1.0 \\
\pm 0.1 \\
\end{array}$ & $\begin{array}{c}1.9 \\
\pm 0.1 \\
\end{array}$ & - & - & $\begin{array}{c}0.3 \\
\pm 0.02 \\
\end{array}$ & $\begin{array}{c}1.6 \\
\pm 0.02 \\
\end{array}$ & - & - \\
\hline hBrr2 ${ }^{\mathrm{CC}}$ & SE & - & - & $\begin{array}{c}0.5 \\
\pm 0.01\end{array}$ & $\begin{array}{c}2.0 \\
\pm 0.2\end{array}$ & - & - & $\begin{array}{c}0.1 \\
\pm 0.001\end{array}$ & $\begin{array}{c}2.0 \\
\pm 0.2\end{array}$ \\
\hline hBrr2 $2^{\mathrm{FL}}$ & $\mathrm{DE}$ & $\begin{array}{c}2.8 \\
\pm 0.03\end{array}$ & $\begin{array}{c}1.5 \\
\pm 0.02\end{array}$ & $\begin{array}{c}0.4 \\
\pm 0.01\end{array}$ & $\begin{array}{c}1.0 \\
\pm 0.1\end{array}$ & $\begin{array}{c}1.0 \\
\pm 0.02\end{array}$ & $\begin{array}{c}1.5 \\
\pm 0.04\end{array}$ & $\begin{array}{c}0.1 \\
\pm 0.01\end{array}$ & $\begin{array}{c}1.0 \\
\pm 0.1\end{array}$ \\
\hline hBrr2 $2^{\mathrm{T} 1}$ & $\mathrm{DE}$ & $\begin{array}{c}2.5 \\
\pm 0.1\end{array}$ & $\begin{array}{c}1.3 \\
\pm 0.02\end{array}$ & $\begin{array}{c}0.4 \\
\pm 0.02\end{array}$ & $\begin{array}{c}1.0 \\
\pm 0.1\end{array}$ & $\begin{array}{c}2.5 \\
\pm 0.03\end{array}$ & $\begin{array}{c}1.2 \\
\pm 0.04\end{array}$ & $\begin{array}{c}0.1 \\
\pm 0.01\end{array}$ & $\begin{array}{c}0.9 \\
\pm 0.01\end{array}$ \\
\hline R603A & $\mathrm{DE}$ & $\begin{array}{c}0.2 \\
\pm 0.03 \\
\end{array}$ & $\begin{array}{c}1.4 \\
\pm 0.04 \\
\end{array}$ & $\begin{array}{c}0.02 \\
\pm 0.001 \\
\end{array}$ & $\begin{array}{c}1.0 \\
\pm 0.1 \\
\end{array}$ & $\begin{array}{c}0.3 \\
\pm 0.03 \\
\end{array}$ & $\begin{array}{c}1.0 \\
\pm 0.04 \\
\end{array}$ & $\begin{array}{c}0.02 \\
\pm 0.001 \\
\end{array}$ & $\begin{array}{c}1.0 \\
\pm 0.2 \\
\end{array}$ \\
\hline R637A & $\mathrm{DE}$ & $\begin{array}{c}3.4 \\
\pm 0.2 \\
\end{array}$ & $\begin{array}{c}1.2 \\
\pm 0.03 \\
\end{array}$ & $\begin{array}{c}0.5 \\
\pm 0.01 \\
\end{array}$ & $\begin{array}{c}1.0 \\
\pm 0.1 \\
\end{array}$ & $\begin{array}{c}0.4 \\
\pm 0.04 \\
\end{array}$ & $\begin{array}{c}1.0 \\
\pm 0.1 \\
\end{array}$ & $\begin{array}{c}0.02 \\
\pm 0.001 \\
\end{array}$ & $\begin{array}{c}1.0 \\
\pm 0.04 \\
\end{array}$ \\
\hline S1087L $L^{b}$ & $\mathrm{DE}$ & $\begin{array}{c}2.7 \\
\pm 0.1 \\
\end{array}$ & $\begin{array}{c}1.4 \\
\pm 0.04\end{array}$ & $\begin{array}{c}0.5 \\
\pm 0.01\end{array}$ & $\begin{array}{c}1.0 \\
\pm 0.03 \\
\end{array}$ & $\begin{array}{c}2.2 \\
\pm 0.21\end{array}$ & $\begin{array}{c}1.4 \\
\pm 0.04\end{array}$ & $\begin{array}{c}0.1 \\
\pm 0.004\end{array}$ & $\begin{array}{c}1.0 \\
\pm 0.4\end{array}$ \\
\hline PPP1296-8AAA & $\mathrm{DE}$ & $\begin{array}{c}2.9 \\
\pm 0.1\end{array}$ & $\begin{array}{c}2.2 \\
\pm 0.1\end{array}$ & $\begin{array}{c}0.52 \\
\pm 0.003 \\
\end{array}$ & $\begin{array}{c}2.0 \\
\pm 0.04\end{array}$ & $\begin{array}{c}0.5 \\
\pm 0.03\end{array}$ & $\begin{array}{c}2.2 \\
\pm 0.1\end{array}$ & $\begin{array}{c}0.03 \\
\pm 0.002\end{array}$ & $\begin{array}{c}2.0 \\
\pm 0.4\end{array}$ \\
\hline GK1355-6QE & SE & $\begin{array}{c}1.3 \\
\pm 0.1 \\
\end{array}$ & $\begin{array}{c}1.5 \\
\pm 0.02 \\
\end{array}$ & - & - & $\begin{array}{c}0.4 \\
\pm 0.02 \\
\end{array}$ & $\begin{array}{c}1.7 \\
\pm 0.1 \\
\end{array}$ & - & - \\
\hline H1548A & $\mathrm{DE}$ & $\begin{array}{c}3.3 \\
\pm 0.3\end{array}$ & $\begin{array}{c}1.2 \\
\pm 0.1\end{array}$ & $\begin{array}{c}0.5 \\
\pm 0.01\end{array}$ & $\begin{array}{c}1.0 \\
\pm 0.3\end{array}$ & $\begin{array}{c}0.2 \\
\pm 0.02\end{array}$ & $\begin{array}{c}1.3 \\
\pm 0.1\end{array}$ & $\begin{array}{c}0.02 \\
\pm 0.001\end{array}$ & $\begin{array}{c}1.0 \\
\pm 0.03\end{array}$ \\
\hline
\end{tabular}

a SE, single-exponential; DE, double exponential.

b S1087L in the N-terminal HB domain originates from a retinitis pigmentosa-linked mutation of hBrr2, and was carried along as a negative control.

Table 2. Affinities of hBrr2 variants for mant-ADP and mant-ATP $\gamma \mathrm{S}$.

\begin{tabular}{|c|c|c|c|c|}
\hline \multirow{3}{*}{ Protein } & \multicolumn{2}{|c|}{ mant-ADP } & \multicolumn{2}{|c|}{ mant-ATP $\gamma \mathrm{S}$} \\
\hline & $\mathrm{NC}$ & $\mathrm{CC}$ & $\mathrm{NC}$ & $\mathrm{CC}$ \\
\hline & $\begin{array}{c}\boldsymbol{K}_{d} \\
{[\boldsymbol{\mu M}]}\end{array}$ & $\begin{array}{c}K_{d} \\
{[\mathrm{nM}]}\end{array}$ & $\begin{array}{c}\boldsymbol{K}_{d} \\
{[\mu \mathrm{M}]}\end{array}$ & $\begin{array}{c}K_{d} \\
{[\mathbf{n M}]}\end{array}$ \\
\hline hBrr2 $2^{\mathrm{NC}}$ & $2.0 \pm 0.2$ & - & $5.8 \pm 0.4$ & - \\
\hline hBrr2 $2^{\mathrm{CC}}$ & - & $4 \pm 0.4$ & - & $30 \pm 3$ \\
\hline hBrr2 $2^{\mathrm{FL}}$ & $0.5 \pm 0.01$ & $2 \pm 0.2$ & $1.6 \pm 0.1$ & $10 \pm 1$ \\
\hline hBrr2 $2^{\mathrm{T} 1}$ & $0.5 \pm 0.02$ & $2 \pm 0.3$ & $0.5 \pm 0.02$ & $10 \pm 1$ \\
\hline R603A & $6.3 \pm 0.8$ & $50 \pm 4$ & $4.1 \pm 0.5$ & $50 \pm 10$ \\
\hline R637A & $0.4 \pm 0.2$ & $2 \pm 0.1$ & $2.6 \pm 0.03$ & $40 \pm 2$ \\
\hline S1087L $^{a}$ & $0.5 \pm 0.02$ & $2 \pm 0.1$ & $0.6 \pm 0.1$ & $10 \pm 4$ \\
\hline PPP1296-8AAA & $0.8 \pm 0.05$ & $4 \pm 0.1$ & $4.3 \pm 0.4$ & $60 \pm 10$ \\
\hline GK1355-6QE & $1.2 \pm 0.05$ & - & $4.4 \pm 0.3$ & - \\
\hline H1548A & $0.4 \pm 0.04$ & $2 \pm 0.6$ & $5.9 \pm 0.6$ & $40 \pm 2$ \\
\hline
\end{tabular}

a S1087L in the N-terminal HB domain originates from a retinitis pigmentosa-linked mutation of hBrr2, and was carried along as a negative control. 
bioRxiv preprint doi: https://doi.org/10.1101/2021.01.28.428616; this version posted January 30, 2021. The copyright holder for this preprint (which was not certified by peer review) is the author/funder, who has granted bioRxiv a license to display the preprint in perpetuity. It is made available under aCC-BY-NC-ND 4.0 International license.

Long-range allosteric effects in an RNA helicase

Table 3. Participation of mutated residues and of E602 and H1534 in the $k$-shortest paths $(k=10)$.

\begin{tabular}{|c|c|c|c|c|c|}
\hline Path & $\mathrm{NC}-\mathrm{CC}$ & NC-CC ${ }^{\text {ATP }}$ & $\mathrm{NC}^{\mathrm{ADP}}-\mathrm{CC}$ & $\mathrm{NC}^{\mathrm{ADP}}-\mathrm{CC}^{\mathrm{ATP}}$ & $\mathrm{NC}^{\mathrm{ATP}}-\mathrm{CC}^{\mathrm{ATP}}$ \\
\hline E616-E1455 & R637 & $\begin{array}{c}\text { E602, R637, } \\
\text { K1544, H1548 }\end{array}$ & $\begin{array}{c}\text { E602, R637, } \\
\text { H1534 }\end{array}$ & R603 & $\begin{array}{c}\text { E602, K1544, } \\
\text { H1548 }\end{array}$ \\
\hline K509-K1356 & R637 & $\begin{array}{l}\text { E602, K1544, } \\
\text { H1548, T1578 }\end{array}$ & E602, H1534 & E602, R603 & \\
\hline N820-N1692 & R603, H1534 & $\begin{array}{c}\text { E602, K1544, } \\
\text { H1548 }\end{array}$ & $\begin{array}{c}\text { E602, R637, } \\
\text { H1534 }\end{array}$ & R603 & $\begin{array}{c}\text { E602, K1544, } \\
\text { H1548 }\end{array}$ \\
\hline Q484-Q1332 & $\begin{array}{c}\text { E602, R637, } \\
\text { H1534 }\end{array}$ & $\begin{array}{c}\text { E602, K1544, } \\
\text { H1548 }\end{array}$ & $\begin{array}{c}\text { E602, H1534, } \\
\text { F1717 }\end{array}$ & R603 & $\begin{array}{c}\text { E602, K1544, } \\
\text { H1548 }\end{array}$ \\
\hline R855-E1455 & R603, R637 & $\begin{array}{c}\text { E602, K1544, } \\
\text { H1548 }\end{array}$ & $\begin{array}{c}\text { E602, R637, } \\
\text { H1534 }\end{array}$ & R603, R637 & E578, H1534 \\
\hline T510-T1357 & R637 & $\begin{array}{c}\text { K1544, } \\
\text { H1548,T1578 }\end{array}$ & $\begin{array}{c}\text { E602, R1195, } \\
\text { H1534 }\end{array}$ & R603 & $\begin{array}{c}\text { E602, K1544, } \\
\text { H1548 }\end{array}$ \\
\hline
\end{tabular}


bioRxiv preprint doi: https://doi.org/10.1101/2021.01.28.428616; this version posted January 30, 2021. The copyright holder for this preprint (which was not certified by peer review) is the author/funder, who has granted bioRxiv a license to display the preprint in perpetuity. It is made available under aCC-BY-NC-ND 4.0 International license.

Long-range allosteric effects in an RNA helicase

\section{FIGURES AND FIGURE LEGENDS}

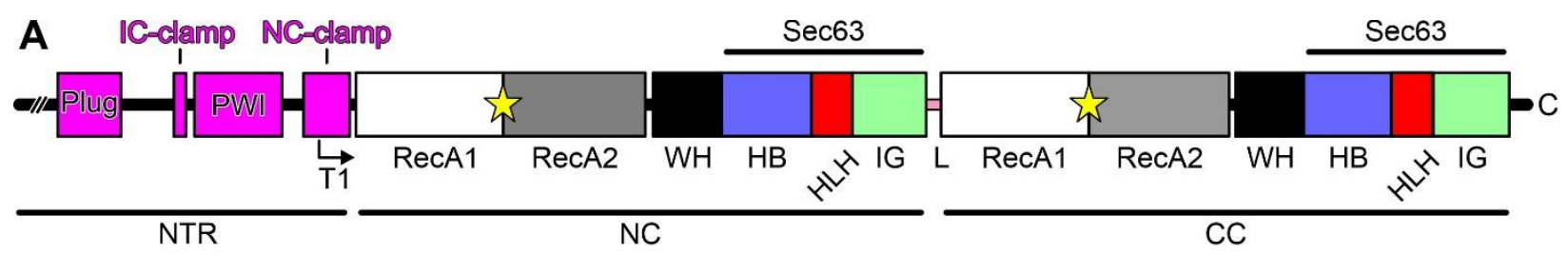

B
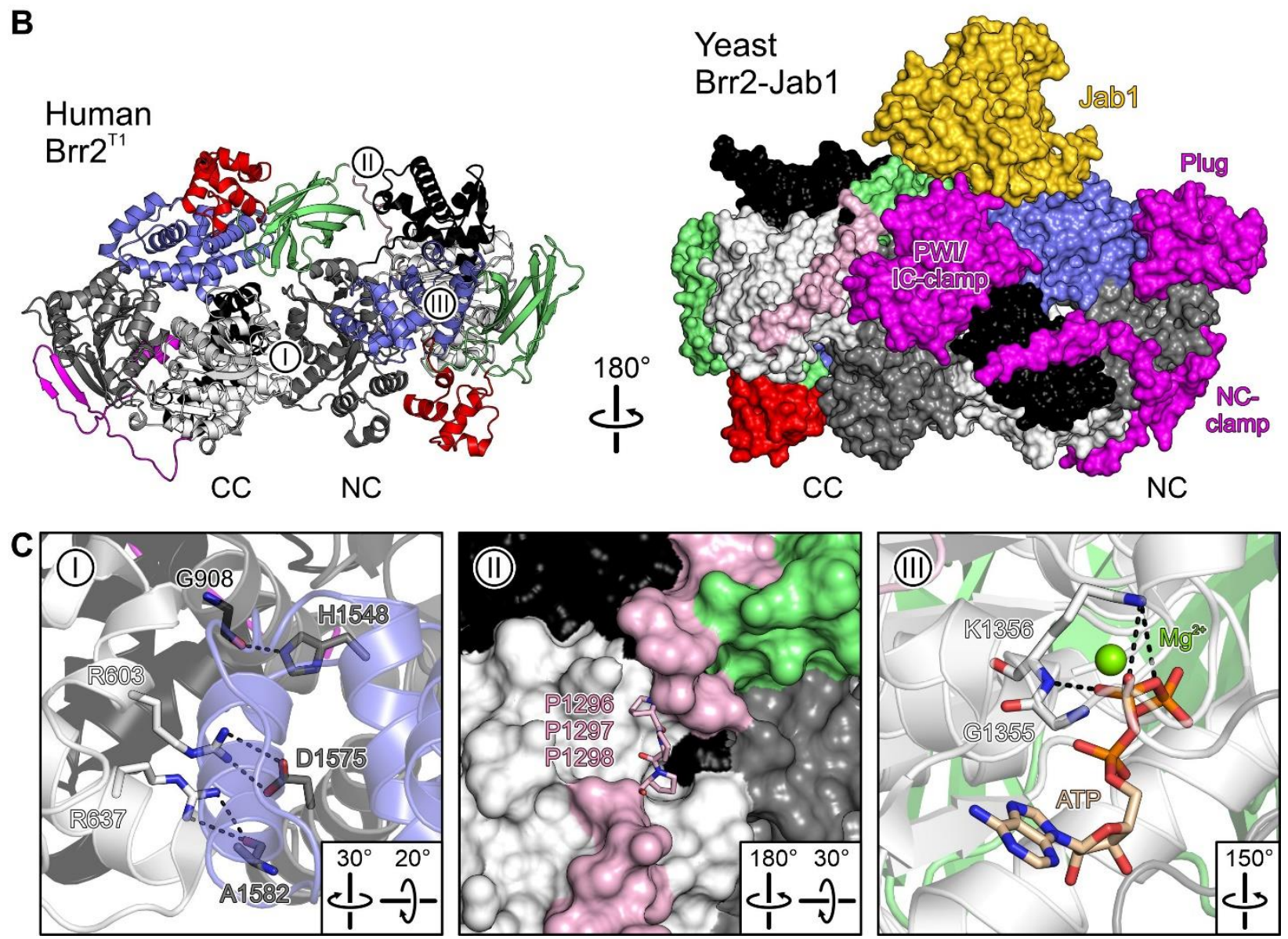

Figure 1. Brr2 organization. A. Domain organization of hBrr2. Angled arrow, starting position of the T1 truncation variant. NTR, N-terminal region; NC, N-terminal cassette; CC, C-terminal cassette; RecA, RecA-like domain; WH, winged helix domain; HB, helical bundle domain; HLH, helix-loop-helix domain; IG, immunoglobulin-like domain; L, linker. Yellow stars, nucleotide binding pockets. B. Structures of $\mathrm{hBrr}^{\mathrm{T} 1}$ (PDB ID 4F91; left) and yBrr2 ${ }^{\mathrm{FL}}$-Jab1 complex (PDB ID 5DCA; right). I-III, regions mutated (see C). Domain coloring as in A; Jab1, gold. Rotation symbol, relative orientation of the panels. C. Details of the mutated regions (I-III as in A, left). ATP-bound structure according to PDB ID 4F93 (region III, right). Relevant residues are shown as sticks. Domain coloring as in A. Residue coloring: Protein carbon, as the respective protein region; ATP carbon, beige; nitrogen, blue; oxygen, red; phosphorus, orange; magnesium ion, green. Dashed lines, hydrogen bonds or salt bridges. 

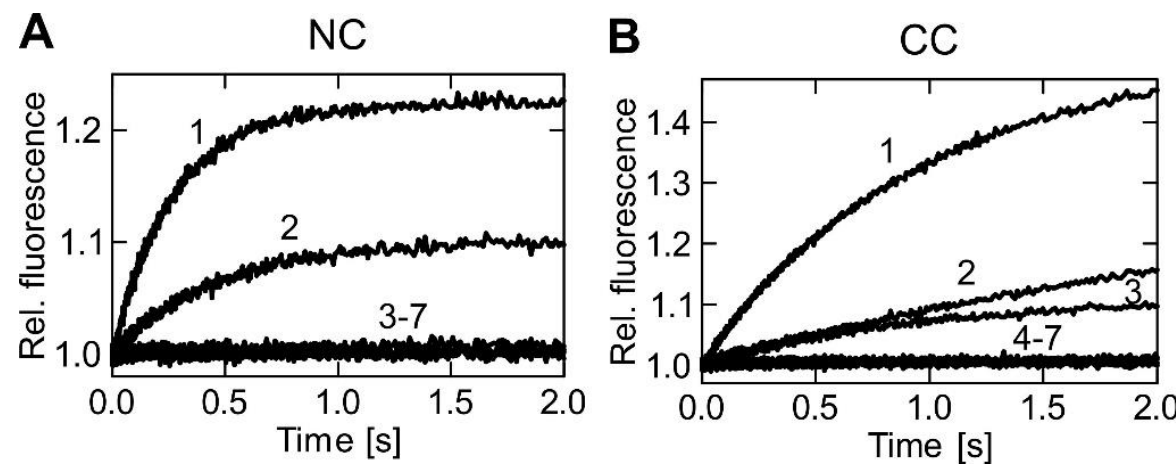

1: Mant-ADP

2: Mant-ATPYS

3: Mant-ATP

4: Mant-AMPPNP

5: Mant-GDP

6: Mant-GTP

7: Mant-GTPYS

Fig. 2. Nucleotide specificity of the hBrr2 cassettes. A and $\mathbf{B}$. Time courses of mant-nucleotide binding to $0.5 \mu \mathrm{M}$ nucleotide-free $\mathrm{hBrr} 2^{\mathrm{NC}}(\mathbf{A})$ and $\mathrm{hBrr} 2^{\mathrm{CC}}(\mathbf{B})$ measured by FRET from Trp to mant. 1, mant-ADP $(5 \mu \mathrm{M}) ; 2$, mant-ATP $\gamma \mathrm{S}(5 \mu \mathrm{M}) ; 3$, mant-ATP $(5 \mu \mathrm{M}) ; 4$, mant-AMPPNP $(5 \mu \mathrm{M}) ; 5$, mant-GDP $(5 \mu \mathrm{M})$; 6 , mant-GTP $(5 \mu \mathrm{M}) ; 7$, mant-GTP $\gamma \mathrm{S}(5 \mu \mathrm{M})$. The hBrr2 cassettes bind mant-ADP and mant-ATP $\gamma \mathrm{S}$ but do not interact with mant-AMPPNP or mant-G nucleotides. 
bioRxiv preprint doi: https://doi.org/10.1101/2021.0128.428616; this version posted January 30,2021. The copyright holder for this preprint (which was not certified by peer review) is the author/funder, who has granted bioRxiv a license to display the preprint in perpetuity. It is made available under aCC-BY-NC-ND 4.0 International license.

Long-range allosteric effects in an RNA helicase

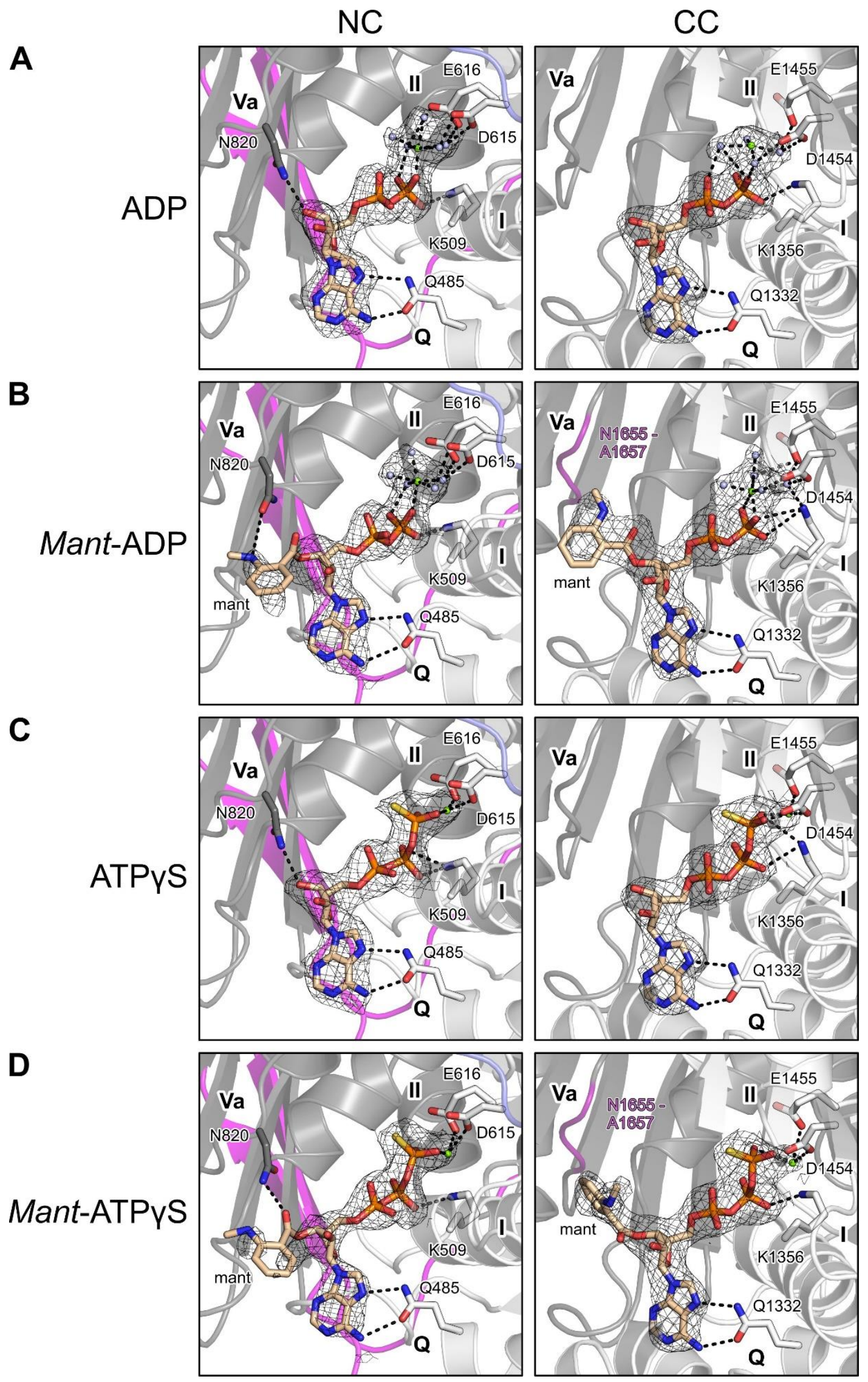


Figure 3. Nucleotide-bound structures. A-D. Binding poses of the indicated nucleotides at the N- and Cterminal cassettes of a hBrr2 $2^{\mathrm{T1}}-\mathrm{hJab} 1^{\Delta \mathrm{C}}$ complex. Meshes, final $2 \mathrm{mF}_{\mathrm{o}}-\mathrm{DF}_{\mathrm{c}}$ electron density maps at the $1 \sigma$ level coving the nucleotides. Left panels, nucleotides bound at NC; right panels, nucleotides bound at CC. Nucleotides, magnesium ions, selected waters and selected Brr2 residues are shown as sticks or small spheres. Domain coloring as in Fig. 1A. Atom/ion coloring: Protein carbon, as the respective protein region; nucleotide carbon, beige; nitrogen, blue; oxygen, red; phosphorus, orange; magnesium ion, green; water oxygen, light blue. Dashed lines, hydrogen bonds, salt bridges or ion coordination. 

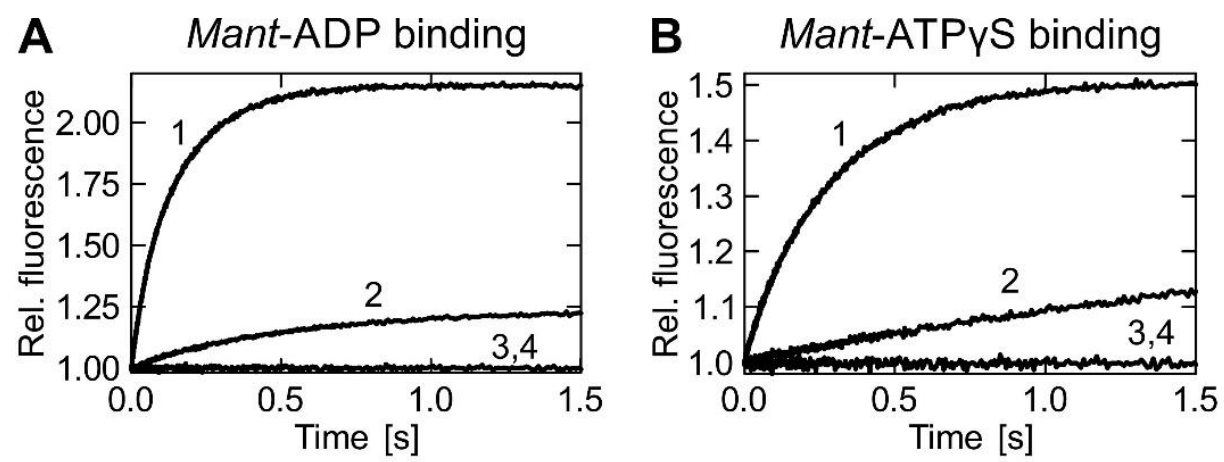

1: $0.4 \mu \mathrm{M} \mathrm{hBrr} 2^{\mathrm{NC}}$
2: $0.2 \mu \mathrm{M} \mathrm{hBrr} 2^{\mathrm{cC}}$

3,4 : Controls
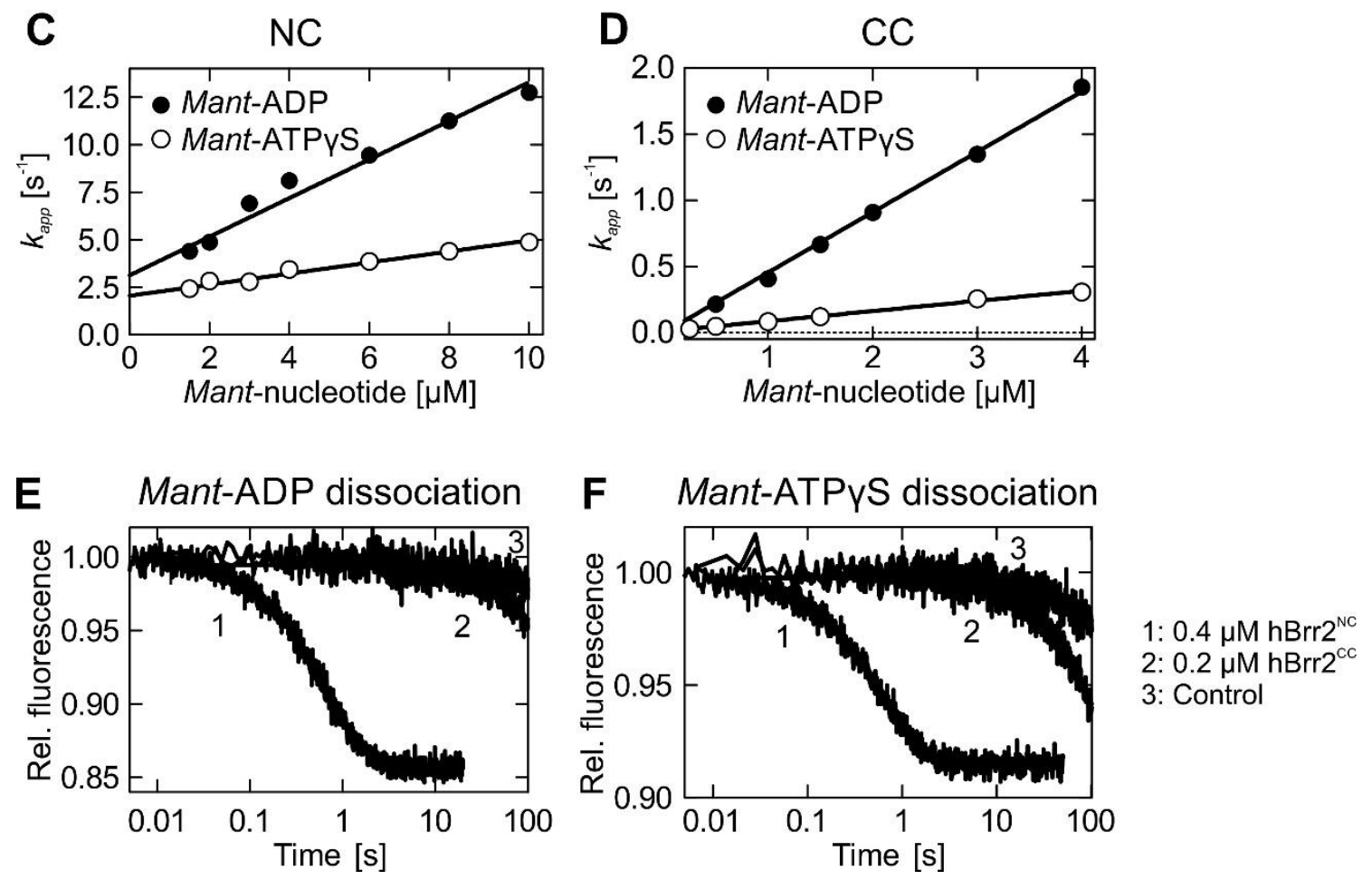

Fig. 4. Kinetics of mant-ADP and mant-ATP $\gamma \mathrm{S}$ interaction with $\mathrm{hBrr2}{ }^{\mathrm{NC}}$ and $\mathrm{hBrr}{ }^{\mathrm{CC}}$. A and $\mathrm{B}$. Time courses of $5 \mu \mathrm{M}$ mant-ADP $(\mathbf{A})$ or mant-ATP $\gamma \mathrm{S}(\mathbf{B})$ binding to hBrr2 ${ }^{\mathrm{NC}}(1 ; 0.4 \mu \mathrm{M})$ and $\mathrm{hBrr} 2^{\mathrm{CC}}(2 ; 0.2$ $\mu \mathrm{M})$ measured by FRET from Trp to mant. Controls correspond to binding experiments with unlabeled $\mathrm{ADP}$ or ATP $\gamma \mathrm{S}$ (3 and 4). C and D. Individual nucleotide binding traces were fitted to single exponentials and the dependencies of the apparent rate constants on nucleotide concentration for $\mathrm{hBrr} 2^{\mathrm{NC}}(\mathbf{C})$ and $\mathrm{hBrr} 2^{\mathrm{CC}}(\mathbf{D})$ were fitted by a linear equation, $k_{a p p}=k_{l}[$ mant-nucleotide $]+k_{-l}$, in which $k_{l}$ is derived from the slope and $k_{-l}$ from the Y-axis intercept. Closed circles, mant-ADP; open circles, mant-ATP $\gamma \mathrm{S}$. Values represent means $\pm \mathrm{SD}$ of at least three independent measurements. $\mathbf{E}$ and $\mathbf{F}$. Dissociation of $5 \mu \mathrm{M}$ mantADP (E) or mant-ATP $\gamma \mathrm{S}(\mathbf{F})$ from $\mathrm{hBrr} 2^{\mathrm{NC}}\left(1 ; 0.4 \mu \mathrm{M} \mathrm{hBrr} 2^{\mathrm{NC}}\right)$ and $\mathrm{hBrr} 2^{\mathrm{CC}}(2 ; 0.2 \mu \mathrm{M})$ in the presence of the respective unlabeled nucleotide in excess $(100 \mu \mathrm{M})$. Control experiments (3) were carried out in the absence of unlabeled nucleotide (curves shown are for $\mathrm{hBrr} 2^{\mathrm{CC}}$ ). 

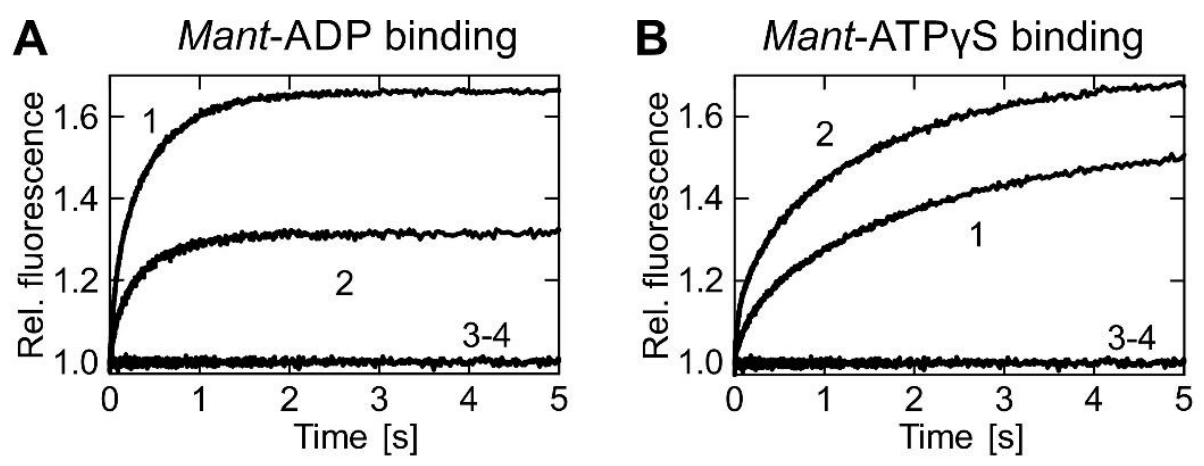

\author{
1: $0.2 \mu \mathrm{M} \mathrm{hBrr} 2^{\mathrm{FL}}$ \\ 2: $0.2 \mu \mathrm{M} \mathrm{hBrr}{ }^{\top 1}$ \\ 3,4 : Controls
}
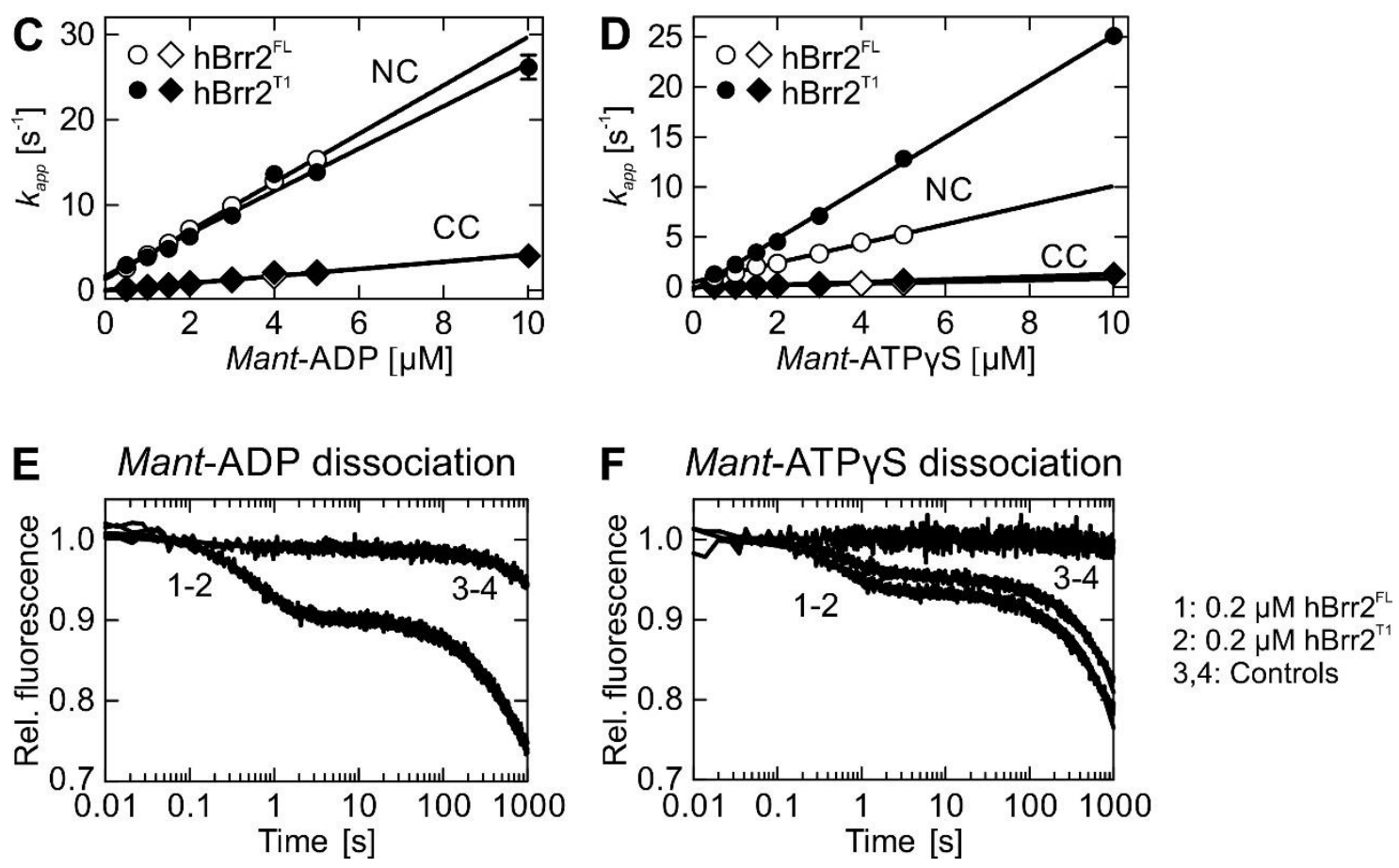

Fig. 5. Kinetics of mant-ADP and mant-ATP $\gamma \mathrm{S}$ interaction with $\mathrm{hBrr} 2^{\mathrm{FL}}$ and $\mathrm{hBrr}^{\mathrm{T} 1}$. A and $\mathrm{B}$. Time courses of $5 \mu \mathrm{M}$ mant-ADP (A) or mant-ATP $\gamma \mathrm{S}(\mathbf{B})$ binding to $\mathrm{hBrr} 2^{\mathrm{FL}}(1 ; 0.2 \mu \mathrm{M})$ and hBrr2 ${ }^{\mathrm{T} 1}(2 ; 0.2$ $\mu \mathrm{M})$ measured by FRET from Trp to mant. Controls were performed with unlabeled ADP or ATP $\gamma \mathrm{S}$ (3-4). $\mathbf{C}$ and D. Individual nucleotide binding traces were fitted to double exponential equations, and the dependence of the apparent rate constants of the NC (circles) and CC (diamonds) on nucleotide concentration were fitted by a linear equation. Open symbols, $\mathrm{hBrr} 2^{\mathrm{FL}}$; closed symbols, $\mathrm{hBrr} 2^{\mathrm{T} 1}$. The cassettes of $\mathrm{hBrr} 2^{\mathrm{FL}}$ and $\mathrm{hBrr} 2^{\mathrm{T} 1}$ bind nucleotides with different velocities as observed for the variants containing either one of the cassettes, $\mathrm{hBrr} 2^{\mathrm{NC}}$ and $\mathrm{hBrr} 2^{\mathrm{CC}}$. While the $\mathrm{CC}$ binds mant-ADP and mant$\mathrm{ATP} \gamma \mathrm{S}$ with similar rates, the $\mathrm{NC}$ in $\mathrm{hBrr} 2^{\mathrm{T} 1}$ binds mant-ATP $\gamma \mathrm{S}$ faster than the $\mathrm{NC}$ in $\mathrm{hBrr} 2^{\mathrm{FL}}$. Values represent means $\pm \mathrm{SD}$ of at least three independent measurements. $\mathbf{E}$ and $\mathbf{F}$. Dissociation of $5 \mu \mathrm{M}$ mant$\operatorname{ADP}(\mathbf{E})$ or mant-ATP $\gamma \mathrm{S}(\mathbf{F})$ from hBrr2 ${ }^{\mathrm{FL}}(1 ; 0.2 \mu \mathrm{M})$ and $\mathrm{hBrr} 2^{\mathrm{T} 1}(2 ; 0.2 \mu \mathrm{M})$ in the presence of the respective unlabeled nucleotide in excess $(100 \mu \mathrm{M})$. Control experiments (3-4) were carried out in the absence of unlabeled nucleotide. 

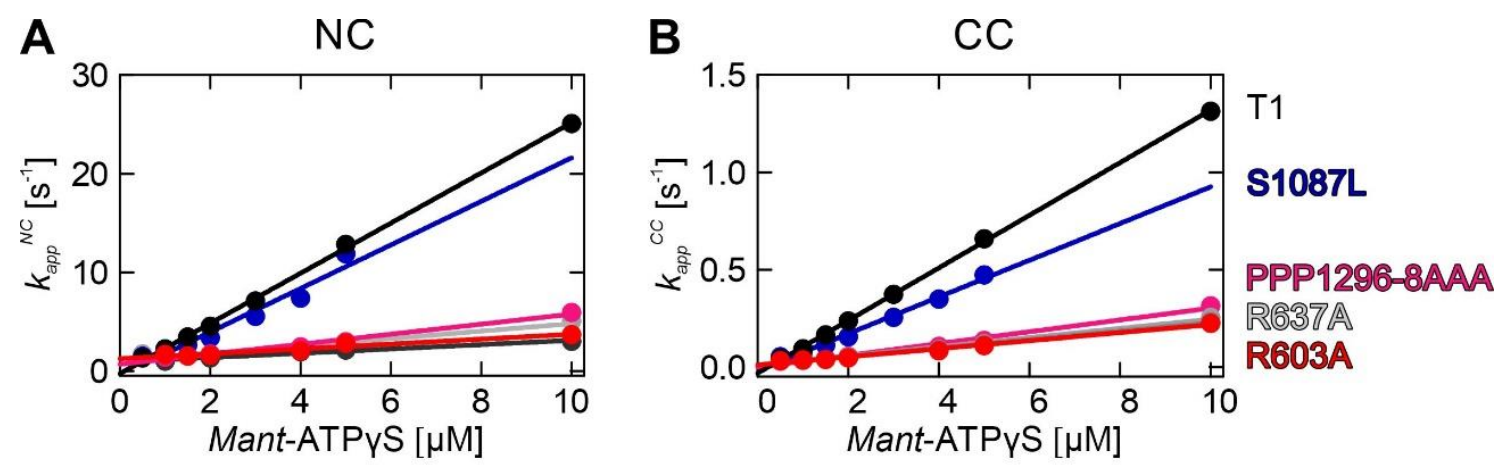
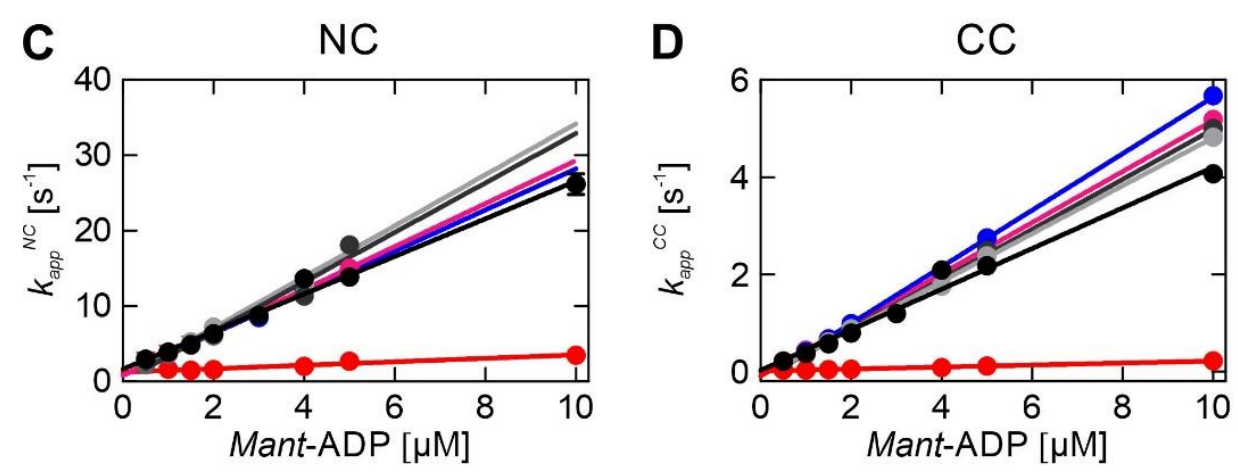

S1087L PPP1296-8AA H1548A R637 T1

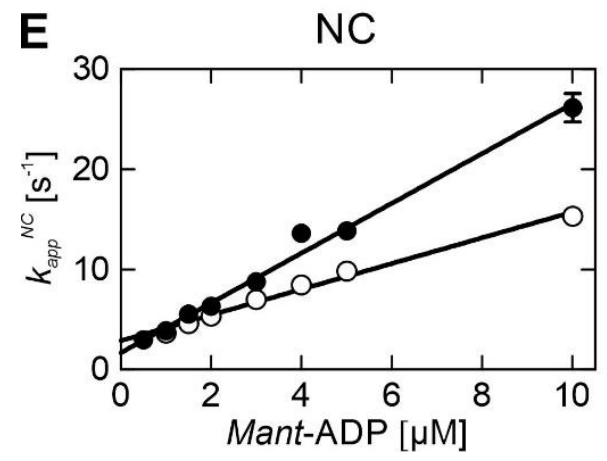

$\mathbf{F}$

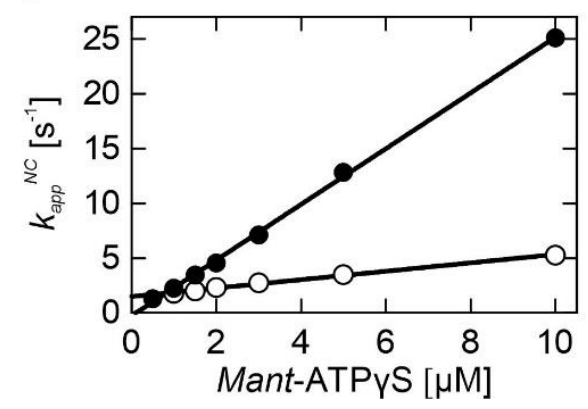

$\mathrm{T} 1$

GK1355-6QE

Fig. 6. Effects of $\mathrm{hBrr}^{\mathrm{T} 1}$ mutations on the kinetics of mant-ADP and mant-ATP $\gamma \mathrm{S}$ binding. A and $\mathrm{B}$. Apparent rate constants $\left(k_{a p p}{ }^{N C}\right.$ and $\left.k_{a p p}{ }^{C C}\right)$ of mant-ATP $\gamma \mathrm{S}$ binding to the respective cassettes in $\mathrm{hBrr} 2^{\mathrm{T} 1}$ and variants thereof. Binding of mant-ATP $\gamma \mathrm{S}$ to either $\mathrm{NC}$ or $\mathrm{CC}$ is affected by all inter-cassette mutations tested. S1087L in the N-terminal HB domain originates from a retinitis pigmentosa-linked mutation of $\mathrm{hBrr} 2$, and was carried along as a negative control. C and D. Apparent rate constants $\left(k_{a p p}{ }^{N C}\right.$ and $\left.k_{a p p}{ }^{C C}\right)$ of mant-ADP binding to the respective cassettes of $\mathrm{hBrr}{ }^{\mathrm{T} 1}$ and variants thereof. While most inter-cassette mutants bind mant-ADP at similar rates as $\mathrm{hBrr}{ }^{\mathrm{T} 1}$, mant-ADP binding is almost completely abrogated at both NC and CC in R603A (red). hBrr2 ${ }^{\mathrm{T} 1}$, black; S1087L (control with residue exchange in the N-terminal HB ratchet helix), blue; R603A (cassette interface NC), red; R637A (cassette interface NC), light gray; PPP1296-8AAA (linker), magenta; H1548A (cassette interface CC), dark gray. Coloring as in A and B. $\mathrm{S} 1087 \mathrm{~L}$ in the N-terminal HB domain originates from a retinitis pigmentosa-linked mutation of hBrr2, and was carried along as a negative control. E and F. Apparent rate constants $\left(k_{a p p}{ }^{N C}\right)$ of mant-ADP and mant$\mathrm{ATP} \gamma \mathrm{S}$ binding to the $\mathrm{NC}$ of $\mathrm{hBrr} 2^{\mathrm{T} 1}$ (closed circles) and its GK1355-6QE variant (altered CC nucleotide binding pocket; open circles). The time courses of nucleotide binding to GK1355-6QE were fitted by a single exponential indicating no detectable nucleotide binding at the $\mathrm{CC}$, as expected due to the two residue exchanges in the CC binding pocket. As GK1355-6QE only has an intact NC nucleotide binding pocket, 
bioRxiv preprint doi: https://doi.org/10.1101/2021.01.28.428616; this version posted January 30, 2021. The copyright holder for this preprint (which was not certified by peer review) is the author/funder, who has granted bioRxiv a license to display the preprint in perpetuity. It is made available under aCC-BY-NC-ND 4.0 International license.

Long-range allosteric effects in an RNA helicase

only the $\mathrm{hBrr} 2^{\mathrm{T} 1} k_{a p p}{ }^{N C}$ is shown for comparison. GK1355-6QE shows reduced rates for nucleotide binding at the NC, suggesting long range modulation of NC nucleotide binding by nucleotide binding at the CC in $\mathrm{hBrr} 2^{\mathrm{T} 1}$. Values represent means $\pm \mathrm{SD}$ of at least three independent measurements. 
bioRxiv preprint doi: https://doi.org/10.1101/2021.01 28.428616; this version posted January 30,2021 . The copyright holder for this preprint (which was not certified by peer review) is the author/funder, who has granted bioRxiv a license to display the preprint in perpetuity. It is made available under aCC-BY-NC-ND 4.0 International license.

Long-range allosteric effects in an RNA helicase
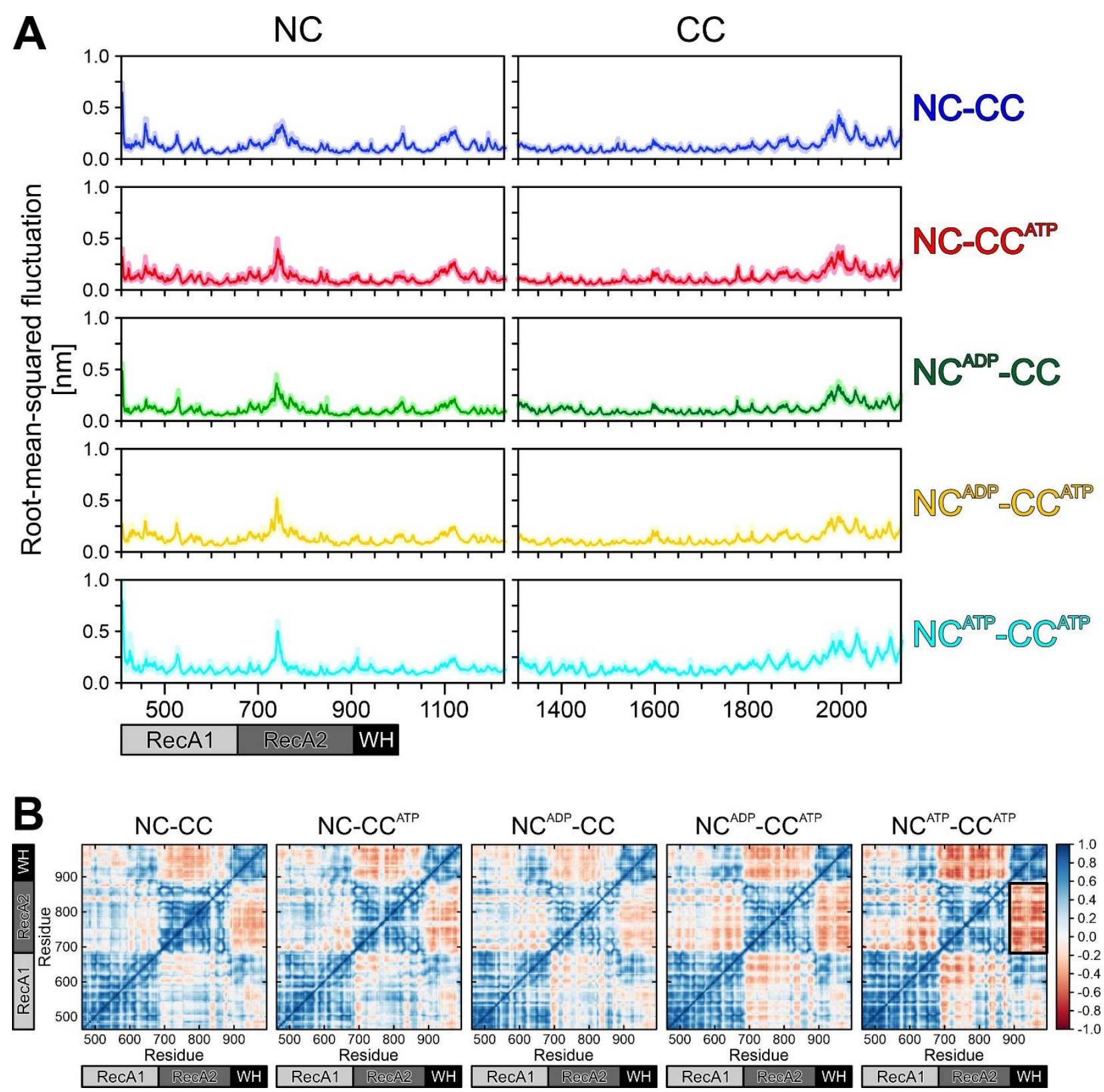

Fig. 7. Brr2 flexibility. A. Flexibility of the NC (left) and of the CC (right) computed as root-mean-squared fluctuation. Solid lines, mean values; shaded areas, SEM, estimated from block averaging of the simulation data (see Methods). B. Linear correlation of positional fluctuations of C $\alpha$ atoms of the RecA1, RecA2, and $\mathrm{WH}$ domains in the $\mathrm{NC}$ of $\mathrm{hBrr} 2^{\mathrm{T} 1}$. Scale bar, degree of linear correlation. 

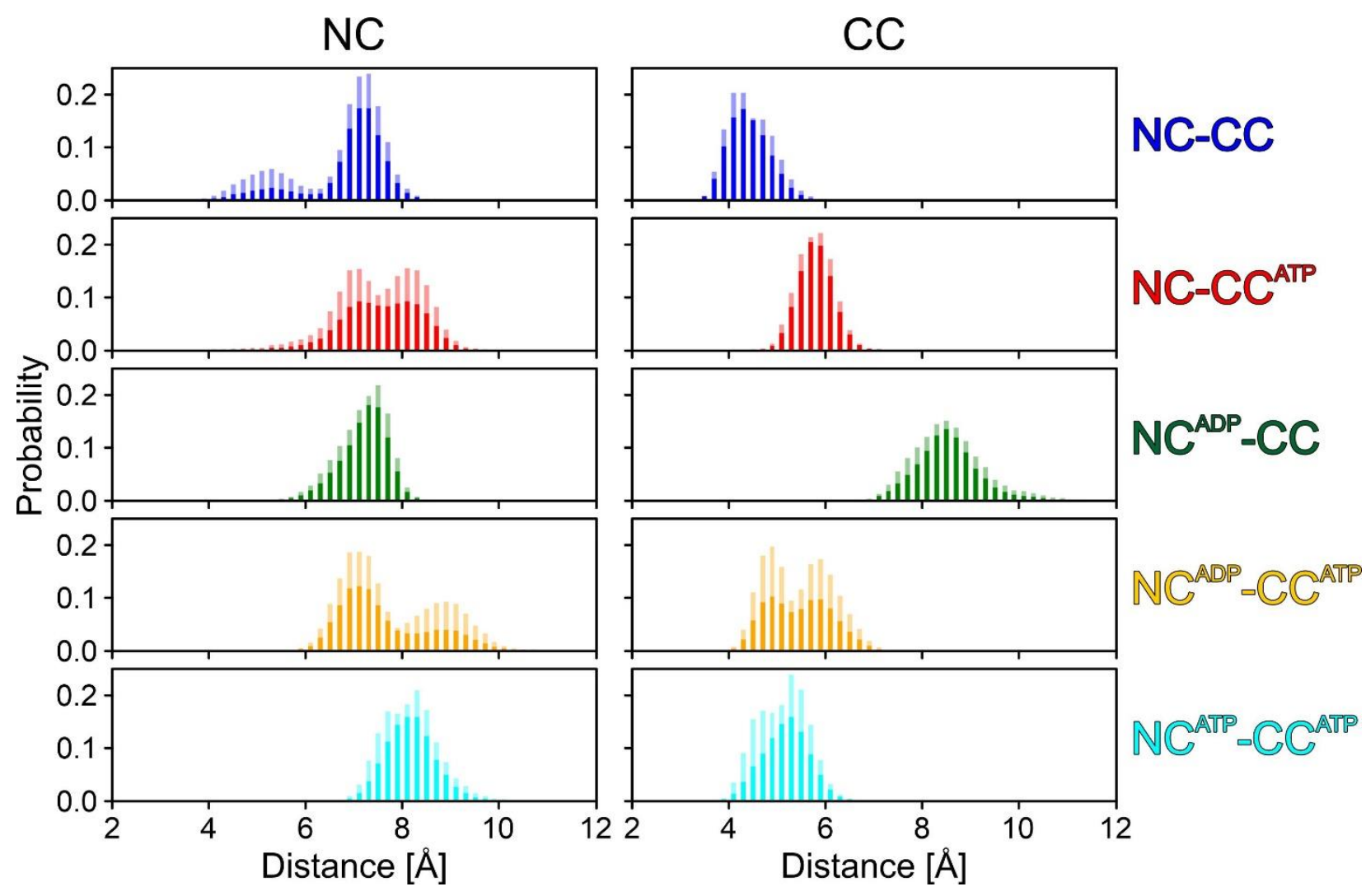

Fig. 8. Widths of the nucleotide binding pockets. Widths of the nucleotide binding pockets of the NC, measured as the distance between G506 and G854 (left), and of the CC, measured as the distance between G1353 and G1689 (right). Solid bars, mean values; transparent bars, SEM, represented as mean + SEM. 
bioRxiv preprint doi: https://doi.org/10.1101/2021.0128.428616; this version posted January 30,2021. The copyright holder for this preprint (which was not certified by peer review) is the author/funder, who has granted bioRxiv a license to display the preprint in perpetuity. It is made available under aCC-BY-NC-ND 4.0 International license.

Long-range allosteric effects in an RNA helicase
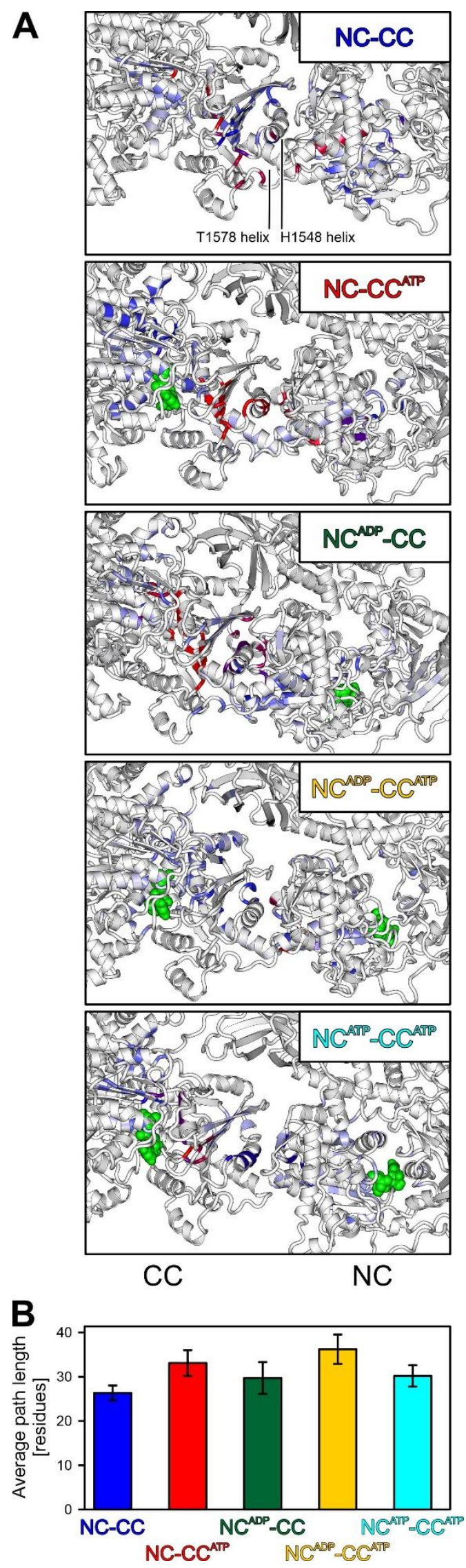
bioRxiv preprint doi: https://doi.org/10.1101/2021.01.28.428616; this version posted January 30, 2021. The copyright holder for this preprint (which was not certified by peer review) is the author/funder, who has granted bioRxiv a license to display the preprint in perpetuity. It is made available under aCC-BY-NC-ND 4.0 International license.

Long-range allosteric effects in an RNA helicase

Fig. 9. Shortest paths. A. Shortest communication paths visualized by highlighting the residues participating in the $k$-shortest pathways between the nucleotide binding pockets of NC and CC by frequency (low-to-high, blue-to-red). Green spheres, bound nucleotides. B. Average path lengths (number of connected residues) of shortest communication paths between the nucleotide binding pockets of NC and CC. Values represent means \pm SEM. 


\section{SUPPLEMENTAL MATERIAL}

\section{Long-range allosteric effects - How adenine nucleotides shape the conformational landscape of the Ski2-like RNA helicase, Brr2}

Eva Absmeier ${ }^{1, \dagger}, \infty$, Karen Vester ${ }^{1, \uparrow}$, Tahereh Ghane $^{2}$, Dmitry Burakovskiy ${ }^{3, \$}$, Pohl Milon ${ }^{4}$, Petra Imhof ${ }^{2, \pi}$, Marina V. Rodnina ${ }^{3}$, Karine F. Santos ${ }^{1, \dagger, \#, *}$, Markus C. Wahl ${ }^{1,5, *}$

From the ${ }^{1}$ Freie Universität Berlin, Structural Biochemistry, Takustr. 6, D-14195 Berlin, Germany; ${ }^{2}$ Freie Universität Berlin, Computational Biophysics, Arnimallee 14, D-14195 Berlin, Germany; ${ }^{3}$ Max Planck

Institute for Biophysical Chemistry, Department of Physical Biochemistry, Am Faßberg 11, D-37077

Göttingen, Germany; ${ }^{4}$ Centre for Research and Innovation, Health Sciences Faculty, Universidad Peruana de Ciencias Aplicadas, Lima, 15023, Perú; ${ }^{5}$ Helmholtz-Zentrum Berlin für Materialien und Energie,

Macromolecular Crystallography, Albert-Einstein-Straße 15, D-12489 Berlin, Germany

$\dagger \quad$ These authors contributed equally to this work.

$\infty$ Present address: MRC Laboratory of Molecular Biology, Francis Crick Avenue, Cambridge CB2 0QH, UK

\$ Present address: Evotec SE, Essener Bogen 7, D-22419 Hamburg, Germany

II Present address: Friedrich-Alexander Universität Erlangen-Nürnberg, Department of Chemistry and Pharmacy, Computational Chemistry Center, Nägelsbachstr. 25, D-91052 Erlangen, Germany

\# Present address: 4TEEN4 Pharmaceuticals GmbH, Neuendorfstr. 15b, D-16761 Hennigsdorf, Germany

* To whom correspondence should be addressed: Karine F. Santos Bourgeois: 4TEEN4 Pharmaceuticals GmbH, Neuendorfstr. 15b, D-16761 Hennigsdorf, Germany; bourgeois@ @teen4.de; Markus C. Wahl: Freie Universität Berlin, Structural Biochemistry, Takustr. 6, D-14195 Berlin, Germany; mwahl@zedat.fu-berlin.de; Tel.: +49-30-838-53456; Fax: +49-30-8384-53456

Running title: Long-range allosteric effects in an RNA helicase

Keywords: Allosteric regulation, enzyme kinetics, intra-molecular regulation, pre-mRNA splicing, protein conformation, RNA helicase, superfamily 2 helicase 
bioRxiv preprint doi: https://doi.org/10.1101/2021.01.28.428616; this version posted January 30,2021 . The copyright holder for this preprint (which was not certified by peer review) is the author/funder, who has granted bioRxiv a license to display the preprint in perpetuity. It is made available under aCC-BY-NC-ND 4.0 International license.

Long-range allosteric effects in an RNA helicase

\section{SUPPLEMENTAL TABLES}

Table S1. Crystallographic data.

\begin{tabular}{|c|c|c|c|c|}
\hline Dataset & 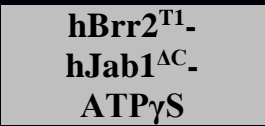 & 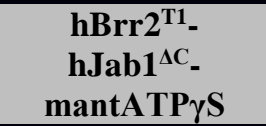 & $\begin{array}{c}\text { hBrr2 }^{\mathrm{T1}}{ }_{-} \\
\text {hJab1 }^{\Delta \mathrm{C}_{-}} \\
\text {ADP }\end{array}$ & $\begin{array}{l}\text { hBrr2 }^{\mathrm{T1}}{ }_{-} \\
\text {hJab1 }^{\Delta \mathrm{C}_{-}} \\
\text {mantADP }^{-}\end{array}$ \\
\hline \multicolumn{5}{|l|}{ Data Collection } \\
\hline Wavelength $[\AA]$ & 0.9184 & 0.9184 & 0.9184 & 0.9184 \\
\hline Temperature $[\mathrm{K}]$ & 100 & 100 & 100 & 100 \\
\hline Space group & $\mathrm{P} 22_{1} 2_{1} 2_{1}$ & $\mathrm{P} 22_{1} 2_{1} 2_{1}$ & $\mathrm{P} 22_{1} 2_{1} 2_{1}$ & $\mathrm{P} 2{ }_{1} 2_{1} 2_{1}$ \\
\hline $\begin{array}{l}\text { Unit cell parameters }[\AA] \\
\quad \text { a, b, c }\end{array}$ & $99.7,118.7,187.2$ & $99.6,118.9,187.4$ & $99.5,118.6,187.2$ & $99.9,118.8,187.8$ \\
\hline Resolution $[\AA]^{\mathrm{a}}$ & \begin{tabular}{|l|}
$50.0-2.8$ \\
$(2.97-2.80)$
\end{tabular} & $\begin{array}{l}50.0-2.6 \\
(2.75-2.60)\end{array}$ & \begin{tabular}{|l|}
$50.0-2.5$ \\
$(2.67-2.50)$
\end{tabular} & $\begin{array}{l}50.0-2.7 \\
(2.86-2.70)\end{array}$ \\
\hline $\begin{array}{l}\text { Reflections } \\
\text { Unique } \\
\text { Completeness [\%] } \\
\text { Redundancy } \\
\end{array}$ & \begin{tabular}{|l}
$55,396(8,662)$ \\
$99.5(97.8)$ \\
$6.7(6.7)$ \\
\end{tabular} & $\begin{array}{l}69,284(10,681) \\
99.3(96.1) \\
6.6(6.6) \\
\end{array}$ & \begin{tabular}{|l}
$74,606(11,542)$ \\
$98.6(95.6)$ \\
$6.7(6.7)$ \\
\end{tabular} & $\begin{array}{l}62,315(9,697) \\
99.5(97.2) \\
6.7(6.7) \\
\end{array}$ \\
\hline $\mathrm{I} / \sigma(\mathbf{I})$ & $6.5(1.0)$ & $8.96(1.0)$ & $7.40(1.0)$ & $7.47(1.0)$ \\
\hline $\mathbf{R}_{\text {meas }}(\mathbf{I})[\%]^{\mathrm{b}}$ & $31.9(222.8)$ & $20.8(212.9)$ & $26.3(210.5)$ & $25.1(185.4)$ \\
\hline $\mathbf{C C}_{1 / 2}[\%]^{\mathrm{c}}$ & $99.0(38.8)$ & $99.7(40.0)$ & 99.3 (35.6) & $99.4(40.4)$ \\
\hline \multicolumn{5}{|l|}{ Refinement } \\
\hline Resolution $[\AA]^{\mathrm{a}}$ & \begin{tabular}{|l|}
$48.2-2.8$ \\
$(2.9-2.8)$ \\
\end{tabular} & \begin{tabular}{|l}
$46.8-2.6$ \\
$(2.69-2.59)$ \\
\end{tabular} & $\begin{array}{l}46.8-2.5 \\
(2.61-2.52) \\
\end{array}$ & $\begin{array}{l}48.3-2.7 \\
(2.79-2.69)\end{array}$ \\
\hline $\begin{array}{l}\text { Reflections } \\
\text { Number } \\
\text { Completeness [\%] } \\
\text { Test set } \\
\end{array}$ & $\begin{array}{l}55,337(5,424) \\
99.83(99.43) \\
2,099(206) \\
\end{array}$ & $\begin{array}{l}69,279(6,469) \\
99.28(93.82) \\
2100(196) \\
\end{array}$ & \begin{tabular}{|l}
$74,594(7053)$ \\
$98.80(94.68)$ \\
$2,100(198)$ \\
\end{tabular} & $\begin{array}{l}62,304(5,860) \\
99.45(95.47) \\
2,100(197) \\
\end{array}$ \\
\hline $\mathbf{R}_{\text {work }}{ }^{\mathrm{d}}$ & $23.7(35.4)$ & $23.0(33.7)$ & $22.8(33.2)$ & $23.2(34.1)$ \\
\hline $\mathbf{R}_{\text {free }}{ }^{e}$ & $29.7(38.4)$ & $28.9(40.2)$ & $28.4(35.9)$ & $29.2(42.6)$ \\
\hline $\begin{array}{l}\text { Contents of A.U. }{ }^{\mathrm{f}} \\
\text { Protein atoms } \\
\text { Ligand atoms } \\
\text { Water oxygens } \\
\end{array}$ & \begin{tabular}{|l|}
15,988 \\
64 \\
217 \\
\end{tabular} & \begin{tabular}{|l}
15,965 \\
84 \\
148 \\
\end{tabular} & \begin{tabular}{|l}
15,884 \\
56 \\
309 \\
\end{tabular} & \begin{tabular}{|l}
15,988 \\
76 \\
292 \\
\end{tabular} \\
\hline $\begin{array}{l}\text { Mean B factors }\left[\AA^{2}\right] \\
\text { Wilson } \\
\text { Protein } \\
\text { Ligands } \\
\text { Water oxygens } \\
\end{array}$ & $\begin{array}{l}55.6 \\
57.0 \\
48.9 \\
42.0 \\
\end{array}$ & $\begin{array}{l}53.7 \\
65.3 \\
79.5 \\
49.8 \\
\end{array}$ & $\begin{array}{l}46.8 \\
55.7 \\
46.6 \\
45.7 \\
\end{array}$ & $\begin{array}{l}53.0 \\
60.3 \\
58.9 \\
43.1 \\
\end{array}$ \\
\hline $\begin{array}{l}\text { Ramachandran plot }^{\mathrm{g}} \\
\text { Favored [\%] } \\
\text { Outliers [\%] }\end{array}$ & $\begin{array}{l}93.44 \\
1.11\end{array}$ & $\begin{array}{l}92.87 \\
0.71\end{array}$ & $\begin{array}{l}95.42 \\
0.46\end{array}$ & $\begin{array}{l}93.8 \\
0.81\end{array}$ \\
\hline $\begin{array}{l}\text { Rmsd }^{\mathrm{h}} \\
\text { Bond lengths }[\AA] \\
\text { Bond angles }\left[{ }^{\circ}\right]\end{array}$ & $\begin{array}{l}0.006 \\
0.58\end{array}$ & $\begin{array}{l}0.003 \\
0.64\end{array}$ & $\begin{array}{l}0.006 \\
0.67\end{array}$ & $\begin{array}{l}0.003 \\
0.53\end{array}$ \\
\hline PDB ID & 7BDI & 7BDJ & 7BDK & $7 \mathrm{BDL}$ \\
\hline
\end{tabular}

a Values in parentheses refer to the highest resolution shells.

b $\quad \mathrm{R}_{\text {meas }}(\mathrm{I})=\sum_{\mathrm{h}}[\mathrm{N} /(\mathrm{N}-1)]^{1 / 2} \sum_{\mathrm{i}}\left|\mathrm{I}_{\mathrm{ih}}-<\mathrm{I}_{\mathrm{h}}>\right| / \sum_{\mathrm{h}} \sum_{\mathrm{i}} \mathrm{I}_{\mathrm{h}}$, in which $\left\langle\mathrm{I}_{\mathrm{h}}>\right.$ is the mean intensity of symmetry-equivalent reflections $\mathrm{h}, \mathrm{I}_{\mathrm{h}}$ is the intensity of a particular observation of $\mathrm{h}$ and $\mathrm{N}$ is the number of redundant observations of reflection h.

c $\mathrm{CC}_{1 / 2}=\left(\left\langle\mathrm{I}^{2}\right\rangle-\langle\mathrm{I}\rangle^{2}\right) /\left(\left\langle\mathrm{I}^{2}\right\rangle-\langle\mathrm{I}\rangle^{2}\right)+\sigma_{\varepsilon}^{2}$, in which $\sigma_{\varepsilon}^{2}$ is the mean error within a half-dataset (84).

d $R_{\text {work }}=\sum_{\mathrm{h}}\left|\mathrm{F}_{\mathrm{o}}-\mathrm{F}_{\mathrm{c}}\right| / \sum \mathrm{F}_{\mathrm{o}}$ (working set, no $\sigma$ cut-off applied). 
bioRxiv preprint doi: https://doi.org/10.1101/2021.01.28.428616; this version posted January 30,2021 . The copyright holder for this preprint (which was not certified by peer review) is the author/funder, who has granted bioRxiv a license to display the preprint in perpetuity. It is made available under aCC-BY-NC-ND 4.0 International license.

Long-range allosteric effects in an RNA helicase

e $R_{\text {free }}$ is the same as $R_{\text {work }}$, but calculated on the test set of reflections excluded from refinement.

A.U. - asymmetric unit.

g Calculated with Phenix.

h Rmsd - root-mean-square deviation from target geometry.

Table S2. Number of hydrogen bonds between protein and nucleotides.

\begin{tabular}{|c|c|c|c|c|}
\hline Cassette & $\mathrm{NC}-\mathrm{CC}^{\mathrm{ATP}}$ & $\mathrm{NC}^{\mathrm{ADP}}-\mathrm{CC}$ & $\mathrm{NC}^{\mathrm{ADP}}-\mathrm{CC}^{\mathrm{ATP}}$ & $\mathrm{NC}^{\mathrm{ATP}}-\mathrm{CC}^{\mathrm{ATP}}$ \\
\hline NC & & $7.8 \pm 0.8$ & $7.0 \pm 1.3$ & $7.5 \pm 2.7$ \\
\hline $\mathrm{CC}$ & $4.0 \pm 0.9$ & & $7.1 \pm 1.1$ & $6.8 \pm 1.1$ \\
\hline
\end{tabular}

Table S3. Hydrogen bond occupancies between the two cassettes [\%].

\begin{tabular}{|l|c|c|c|c|c|}
\hline Hydrogen bond & NC-CC & NC-CC & NCP $^{\text {ADP }}-\mathbf{C C}$ & NC $^{\text {ADP }}-C^{\text {ATP }}$ & NC $^{\text {ATP }}-C^{\text {ATP }}$ \\
\hline E602-T1537 & $71.3 \pm 5.5$ & & & & \\
\hline E602-K1544 & $100.0 \pm 2.9$ & $81.0 \pm 38.9$ & & $100.0 \pm 3.0$ & \\
\hline R603-L1540 & & $52.1 \pm 29.8$ & $60.9 \pm 9.3$ & & \\
\hline R603-D1575 & $100.0 \pm 15.5$ & $100.0 \pm 2.4$ & $100.0 \pm 0.6$ & & $100.0 \pm 25.8$ \\
\hline R637-D1583 & & $100.0 \pm 42.8$ & $68.3 \pm 75.9$ & $100.0 \pm 11.7$ & $100.0 \pm 15.7$ \\
\hline N909-K1544 & & $52.8 \pm 27.5$ & & $74.2 \pm 7.5$ & $67.1 \pm 14.9$ \\
\hline N909-H1548 & & & $48.0 \pm 8.9$ & & \\
\hline Q1191-Y1770 & & $47.7 \pm 19.1$ & & & \\
\hline P1192-N1767 & $64.8 \pm 9.1$ & $49.9 \pm 15.8$ & $65.6 \pm 20.2$ & $52.9 \pm 7.2$ & \\
\hline S1196-K1716 & $51.3 \pm 20.6$ & & & & \\
\hline E1237-S1709 & & & & $42.8 \pm 22.8$ & \\
\hline
\end{tabular}

a Hydrogen bonds of the backbone in italics.

Table S4. Crossing of cassette-cassette interface on shortest paths.

\begin{tabular}{|l|l|l|l|l|l|}
\hline \multicolumn{1}{|c|}{ Path } & NC-CC & NC-CC & NC $^{\text {ADP }}-\mathbf{C C}$ & NC $^{\text {ADP }}-\mathbf{C C}^{\text {ATP }}$ & NC $^{\text {ATP }}-\mathbf{C C}^{\text {ATP }}$ \\
\hline E616-E1455 & R637-D1583 & E602-K1544 & R637-D1583 & R603-L1540 & E602-K1544 \\
\hline K509-K1356 & R637-D1583 & E602-K1544 & Y605-H1534 & R603-D1575 & Q980-Q1528 \\
\hline N820-N1692 & K599-H1534 & E602-K1544 & Y605-H1534 & R603-L1540 & E602-K1544 \\
\hline Q484-Q1332 & E578-H1534 & E602-K1544 & Y605-H1534 & R603-D1575 & E602-K1544 \\
\hline R855-E1455 & R637-D1583 & E602-K1544 & R637-D1583 & R603-L1540 & E578-H1534 \\
\hline T510-T1357 & R637-D1583 & M641-T1578 & Y605-H1534 & R603-D1575 & E602-K1544 \\
\hline
\end{tabular}


bioRxiv preprint doi: https://doi.org/10.1101/2021.01.28.428616; this version posted January 30, 2021. The copyright holder for this preprint (which was not certified by peer review) is the author/funder, who has granted bioRxiv a license to display the preprint in perpetuity. It is made available under aCC-BY-NC-ND 4.0 International license.

Long-range allosteric effects in an RNA helicase

\section{SUPPLEMENTAL FIGURES}

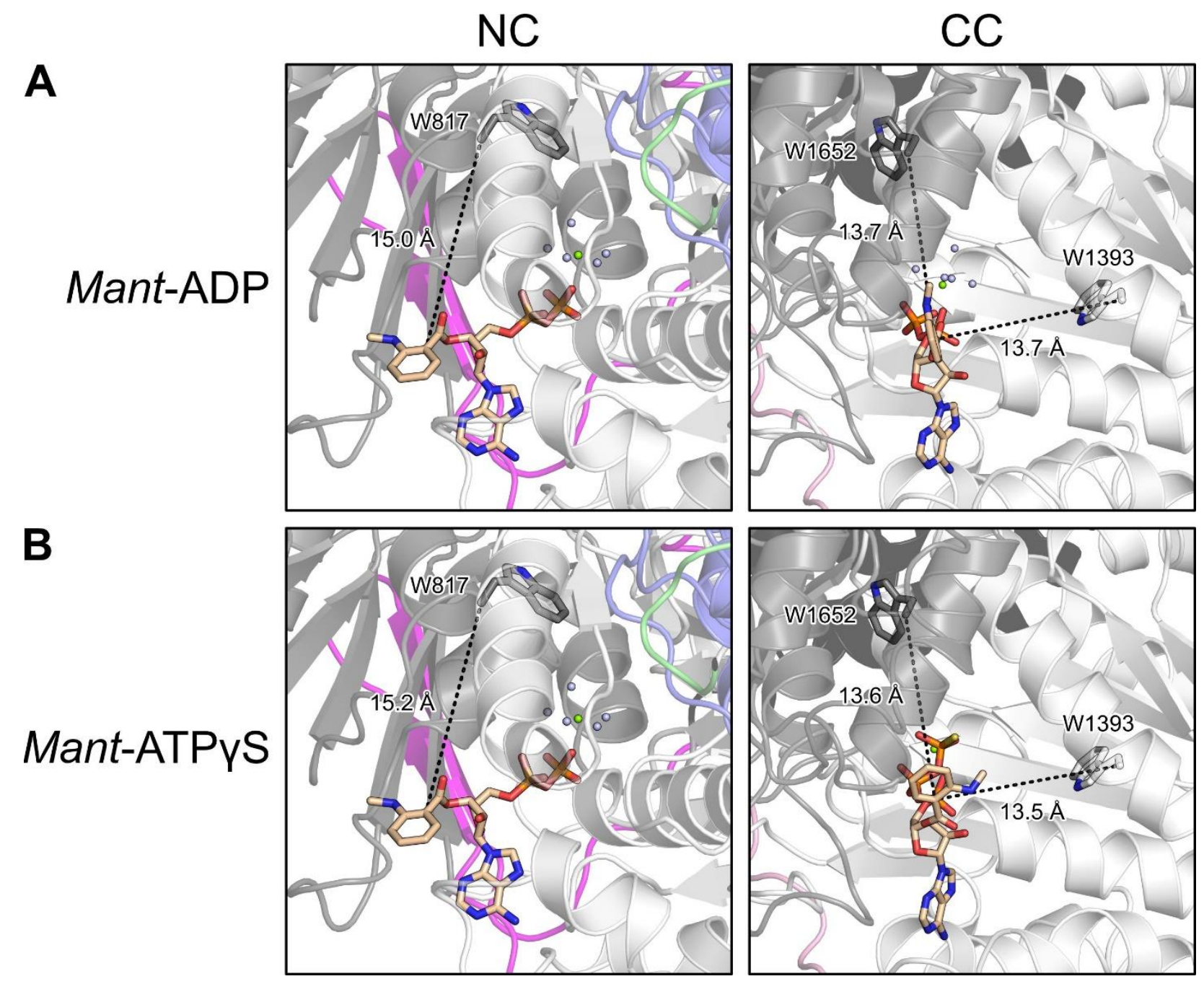

Figure S1. Distances of Trp residues to mant moieties. A and B. Comparison of the distances of the mant moieties in mant-ADP (A) or mant-ATP $\gamma \mathrm{S}(\mathbf{B})$ to the nearest Trp residues around the NC (left) and CC (right) nucleotide binding pockets. Dashed lines, distances between the $\mathrm{C} 8$ atom of the mant-nucleotides to the $\mathrm{C} \alpha$ atoms of the respective Trp residues. 

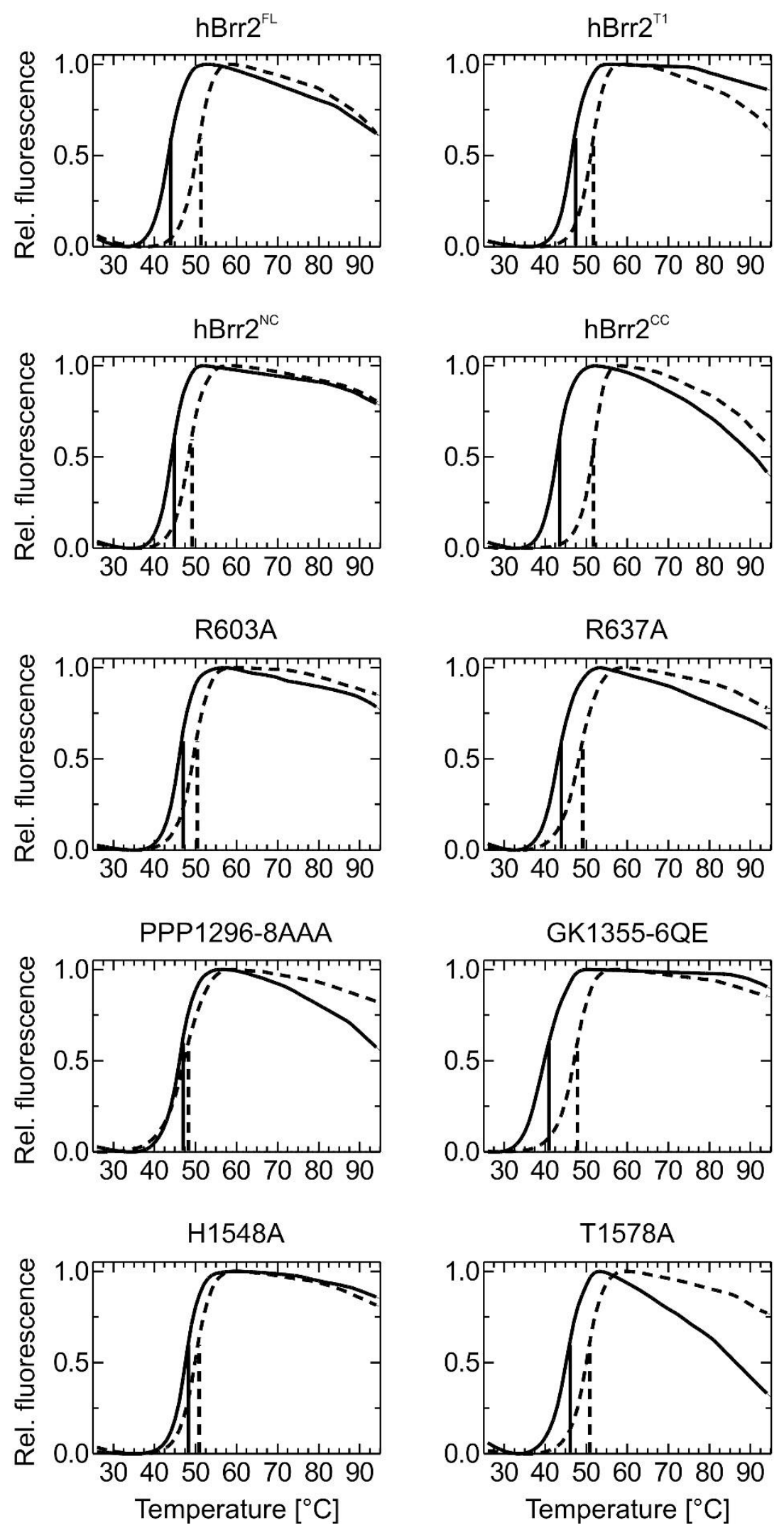

\section{T1578A}

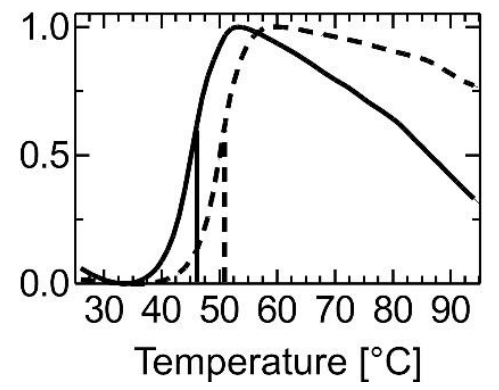


bioRxiv preprint doi: https://doi.org/10.1101/2021.01.28.428616; this version posted January 30, 2021. The copyright holder for this preprint (which was not certified by peer review) is the author/funder, who has granted bioRxiv a license to display the preprint in perpetuity. It is made available under aCC-BY-NC-ND 4.0 International license.

Long-range allosteric effects in an RNA helicase

Figure S2. DSF analyses of the hBrr2 variants used in this work. Solid lines; melting curves obtained in the absence of ATP/ $\mathrm{Mg}^{+2}$; dashed lines, melting curves obtained in the presence of $2 \mathrm{mM} \mathrm{ATP} / \mathrm{Mg}^{+2}$. All variants exhibited cooperative transitions with similar melting temperatures. 